\title{
A Guide to the Design of Surface-Water-Quality Studies
}

by Robert C. Averett and LeRoy J. Schroder

U.S. GEOLOGICAL SURVEY

Open-File Report 93-105 


\section{U.S. DEPARTMENT OF THE INTERIOR \\ BRUCE BABBITT, Secretary}

U.S. GEOLOGICAL SURVEY

Gordon P. Eaton, Director

The use of trade, product, industry, or firm names is for descriptive purposes only and does not imply endorsement by the U.S. Government.

For additional information write to:

Chief, Branch of Quality Assurance

U.S. Geological Survey

Box 25046, MS 401

Denver Federal Center

Denver, CO 80225
Copies of this report can be purchased from:

U.S. Geological Survey

Earth Science Information Center

Open-File Reports Section

Box 25286, MS 517

Denver Federal Center

Denver, CO 80225 


\section{CONTENTS}

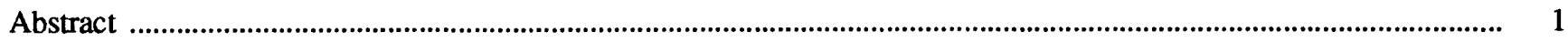

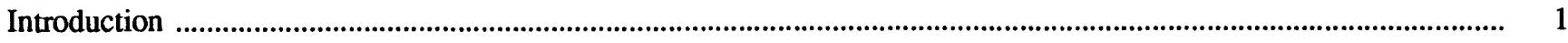

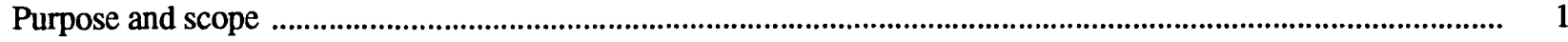

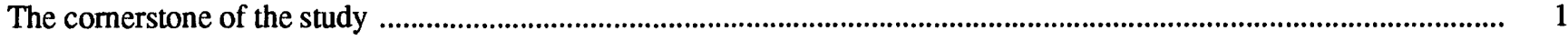

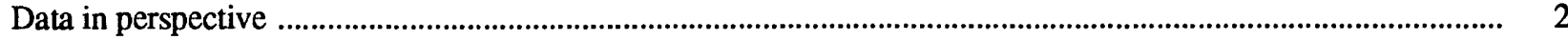

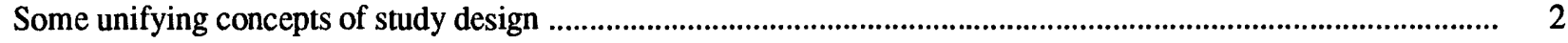

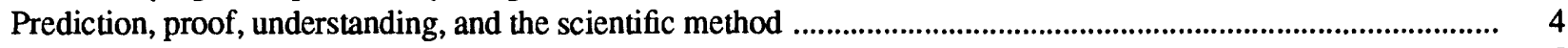

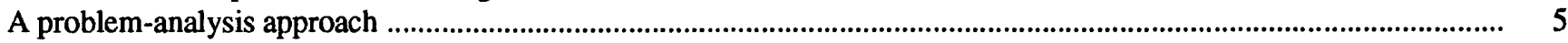

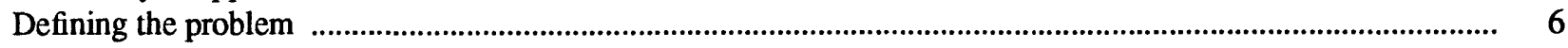

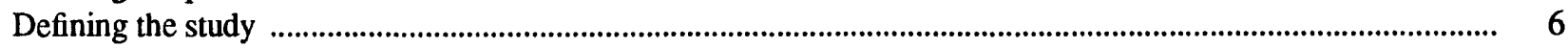

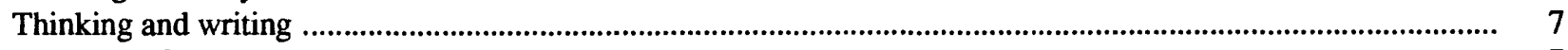

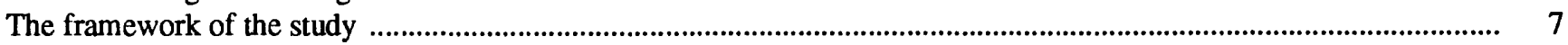

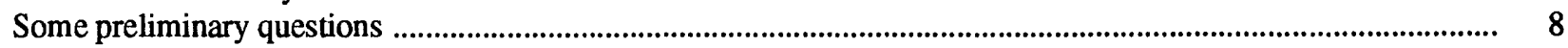

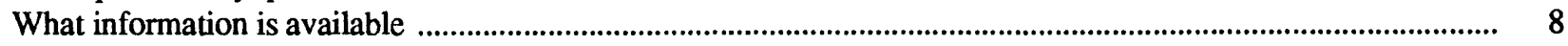

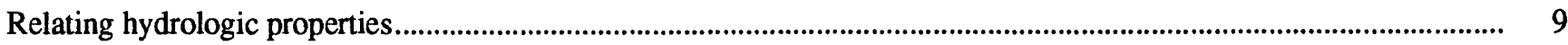

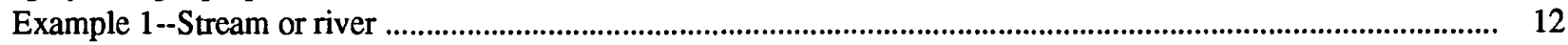

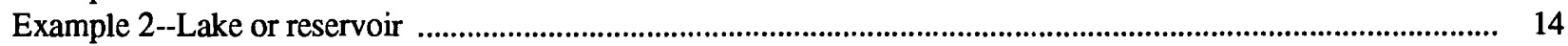

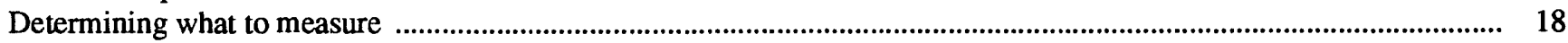

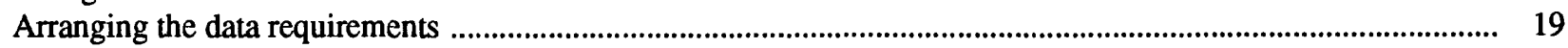

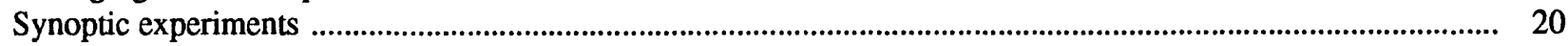

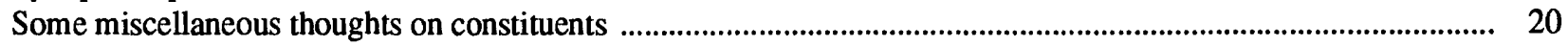

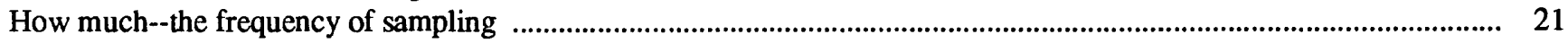

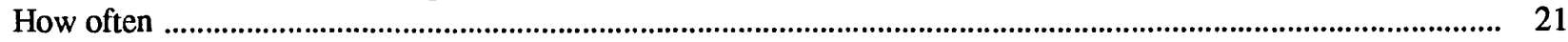

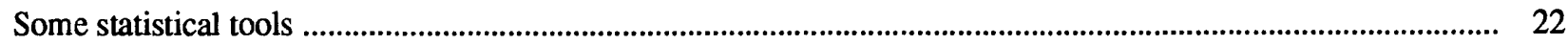

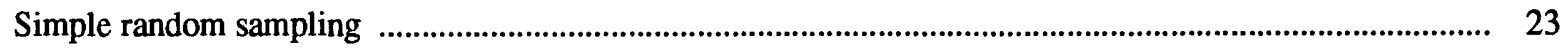

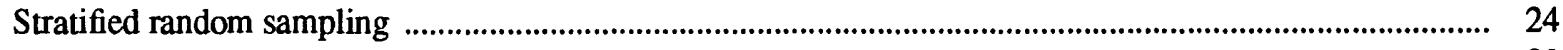

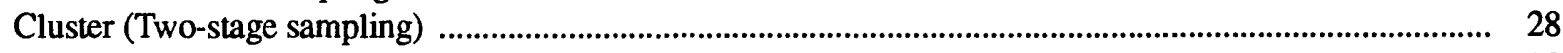

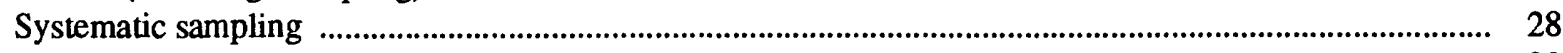

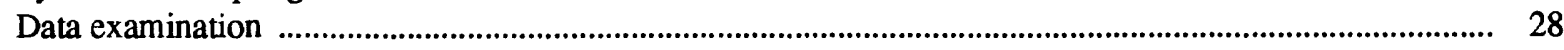

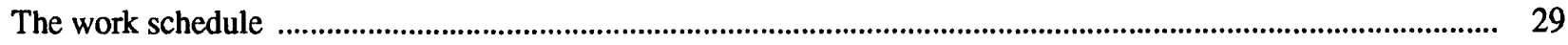

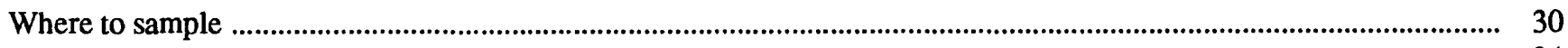

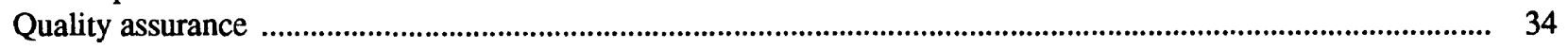

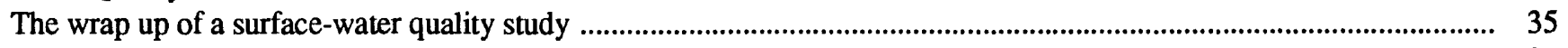

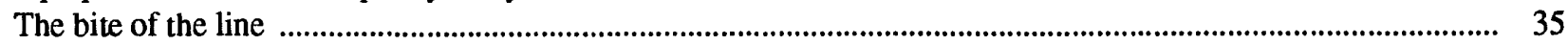

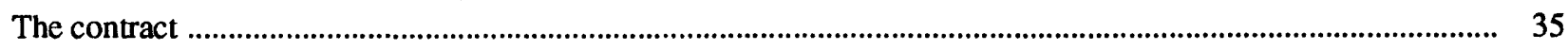

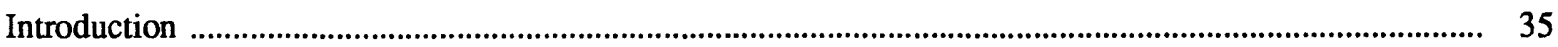

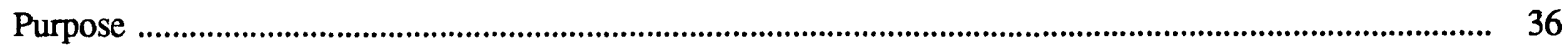

Scope

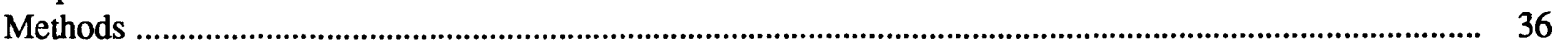

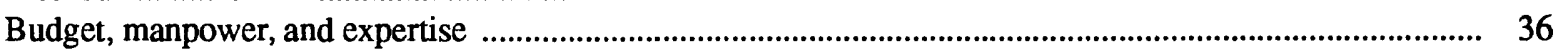

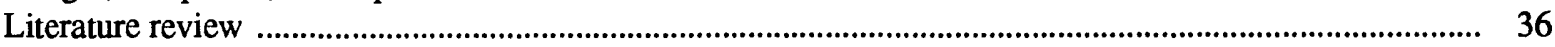

References

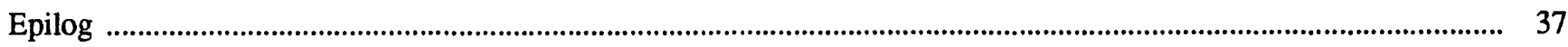

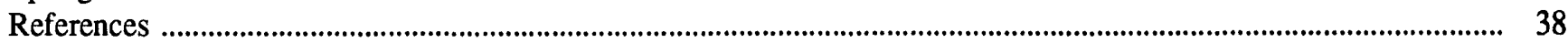




\section{FIGURES}

1. Diagram showing problem solving using inductive and deductive reasoning..

2-4. Graphs showing:

2. An example of the inverse relation between dissolved solids and discharge in the absence of human-induced influences

3. An example hydrograph of the variation of discharge with time.

4. An example of ion concentration related to specific conductance ............................................................. 10

5. Diagram showing examples of possible constituent-distribution patterns in hydrologic systems .......................... 11

6-17. Graphs showing:

6. An example of the distribution of people at a resort area by seasons of the year ....................................... 12

7. Examples of plant growth-production curves by seasons of the year ..................................................... 13

8. An example of water temperature by seasons of the year.................................................................

9. An example of the rate of sewage decomposition at various distances from the sewage outfall ................. 13

10. An example of a discharge hydrograph........................................................................................................ 14

11. An example of different combined curves by seasons of the year .............................................................. 15

12. Water-temperature profiles for a classical temperate-zone lake by seasons of the year ............................. 15

13. Dissolved oxygen profiles for a classical temperate-zone lake by seasons of the year and degree of enrichment ................................................................................................................................ 16

14. An example of a classical phytoplankton-abundance profile by seasons of the year ................................ 17

15. An example of primary-production profiles in a lake ........................................................................... 17

16. An example of constituent concentration in $\mathrm{A}$, an oxygen-unenriched lake and $\mathrm{B}$, an oxygen-enriched lake during the summer .................................................................................................... 18

17. An example of a hydrograph having four strata..................................................................................... 25

\section{TABLES}

1. An example of a data-requirement matrix prepared for studying metal-plating plant discharge to a stream

2. The proportional allocations determined from the example in figure $\mathbf{1 7}$ for the number of samples per stratum

3. Example optimum-allocation table used to determine the sampling frequency for each stratum in the example hydrograph in figure 17.

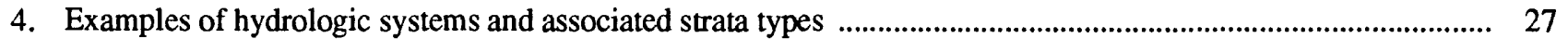

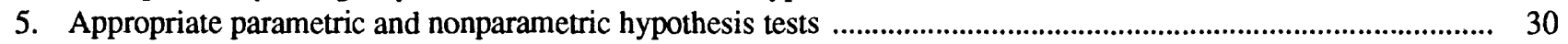

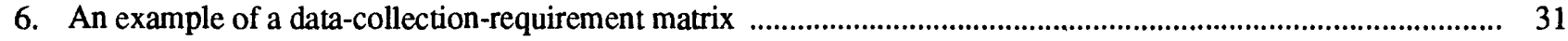




\section{CONVERSION FACTORS}

\begin{tabular}{rll} 
Multiply & By & To obtain \\
\hline & & \\
cubic foot per second $\left(\mathrm{ft}^{3} / \mathrm{s}\right)$ & 0.02832 & cubic meter per second $\left(\mathrm{m}^{3} / \mathrm{s}\right)$ \\
foot $(\mathrm{ft})$ & 0.3048 & meter $(\mathrm{m})$ \\
gallon per minute $(\mathrm{gal} / \mathrm{min})$ & 0.0630 & liter per second $(\mathrm{L} / \mathrm{s})$ \\
inch $(\mathrm{in})$. & 25.40 & millimeter $(\mathrm{mm})$ \\
inch per year $(\mathrm{in} / \mathrm{yr})$ & 25.40 & millimeter per year $(\mathrm{mm} / \mathrm{yr})$ \\
mile $(\mathrm{mi})$ & 1.609 & kilometer $(\mathrm{km})$ \\
cubic meter per second $\left(\mathrm{m}^{3} / \mathrm{s}\right)$ \\
million gallon per day $(\mathrm{Mgal} / \mathrm{d})_{\text {square mile }\left(\mathrm{mi}^{2}\right)}^{0.0438}$ & square kilometer $\left(\mathrm{km}^{2}\right)$ \\
& 2.590 & \\
\hline
\end{tabular}

Degree Fahrenheit $\left({ }^{\circ} \mathrm{F}\right)$ may be converted to degree Celsius $\left({ }^{\circ} \mathrm{C}\right)$ by using the following equation:

$$
{ }^{\circ} \mathrm{C}=5 / 9 \text { ( }{ }^{\circ} \mathrm{F}-32 \text { ). }
$$




\title{
A Guide to the Design of Surface-Water- Quality Studies
}

\author{
By Robert C. Averett and LeRoy J. Schroder
}

\begin{abstract}
Data interpretation is difficult under the simplest of conditions and requires hydrologic studies that are carefully designed. Good research presupposes carefully collected data, as well as data that were obtained at times when the information content was highest. To accomplish the careful design of hydrologic studies and to obtain quality data, the U.S. Geological Survey works through small organizational units. The principles of a well-designed study are: 1) Use the scientific method; 2) define the problem and the approach; 3) state the objectives of the data collection; 4) determine what and how to sample; 5) decide where to sample; 6 ) begin report preparation early in the study; 7) do the work with little or no rework; and 8) complete the report on schedule.
\end{abstract}

\section{INTRODUCTION}

The U.S. Geological Survey (USGS) categorizes its enterprises as data collection or interpretative studies. Data collection often is viewed as an activity whose mission is to acquire information about the occurrence, quality, quantity, distribution, uses, and movement of the Nation's surface and ground waters. Data-collection activities are efforts to obtain the information in a consistent and uniform manner that enables analysis of the findings. Data are reported to our Nation (the users) annually in the USGS annual data reports from the 43 District offices. The users view our data as the source of good-quality information that transcends political boundaries. Interpretative studies also result in reports, and these reports actually "tell a story" about the often complex and multidisciplinary hydrologic processes about which we now have more understanding. These interpretative studies are the mechanisms used to investigate and research the Nation's water resources.

The primary objective of a study is to transform data to information. This objective leads to the central theme of this report, which is that study planning and research are intellectual activities that require much thought and must not be treated as a mechanical pro- cess. The major sections of this report present aids to study chiefs to help them: 1) Determine how a hydrologic system works; 2 ) define the problem and the type of study needed; 3 ) select the measurements to be made; 4) decide on the frequency of data collection; 5) select the sites for sampling; and 6) prepare the work plan and final report.

\section{Purpose and Scope}

This document provides guidance to investigators who must design, manage, and document a scientific study. Application of this guide is equally appropriate for data and interpretative studies.

The suggestions and examples demonstrated in this report provide specific counsel for a study chief. This counsel is provided to clarify the benefits such as:

- Clarity of expectations, to ensure that each chief fully understands what the organization expects from the employee's efforts.

- Consistently valid scientific data.

- A decrease in duplication of work.

- Reports that are produced on time and that meet the organization's standards.

This report presents guidance that can be used to help study chiefs plan, conduct, and conclude a scientific study.

\section{THE CORNERSTONE OF THE STUDY}

The cornerstone of hydrologic investigations is the study chief (project chief in the USGS). You are the one who must maintain the perspective, apply the inductive and deductive reasoning, and use the scientific method. How you set your foundation determines how the study design is built. 


\section{Data in Perspective}

Both new and veteran employees will notice that a large amount of hydrologic data is collected and published. If you are a new employee, you will probably agree that our organization is modern in our data analyses and publication. If you are a veteran employee, you will certainly agree that we now publish many more data, as well as many more types of data, than we did in the past. Today, 1993, we discuss results of measurements and analyses that did not have recognized techniques even 5 to 10 years ago.

While the computer has provided us with the opportunity for a "data explosion," modern instrumentation and measurements have provided us with the opportunity for a "constituent explosion." These "explosions," however, have not been without their attendant problems. More data, obtained at a greater rate, and more constituents, obtained without antecedent hydrologic relations, have placed a heavy burden upon our Regional and District programs. More and more, we are asked to interpret and explain our findings. Our ultimate task is not that of just collecting data; rather, it is to explain the hydrologic significance and relations of the data. Our task is to transform data to information. The collection of data has become the beginning, not the end, because much of our present effort is research or interpretative investigations. No distinction should be made between basic and applied studies; this classification scheme is archaic because it matters little if your study falls into the so-called applied or basic category. It matters greatly if your effort is carefully designed and provides a clean result.

Data interpretation is never a simple task, and the complexities of hydrologic systems make data interpretation difficult under the simplest of conditions. For this reason, hydrologic studies must be carefully designed if useful results and logical conclusions are to be the final product.

Research is an intellectual activity, not just the collection of data; it is the design of a study framework, the data collection scheme, and then, and only then, the analysis of those data. Good research pre-supposes carefully collected data, as well as data that were collected at times when the information content was highest. Don't assume that the previous sentence means that the most sensitive or most precise method of data collection is always required. Simply remember that the users of the information need to be assured that you designed and used a technically valid approach.

As an intellectual activity, research depends upon rational thought and logical stepwise events for its success. It is the design, the application, the comparison, and the intellectual overview that results in a successful research effort. While no one design fits all studies, a number of underlying principles can be followed regardless of the type of study to produce a successful study.

We have all read scientific publications that contain the findings of investigations. We have all noticed that some studies are better than others; some investigators seem to carry out their studies with explicit results and conclusions. This report will discuss aspects of study design used by successful study chiefs. First, let's warm up our thought processes by studying the thoughts and writings of others. Excerpts from Ghent (1966), Ross (1966), Chamberlin (1897), and Platt (1964), have been selected. Others could be listed, but these scientists have said much and have said it well. Learn from them.

\section{Some Unifying Concepts of Study Design}

This section of the report will present some unifying concepts of study design and borrow some ideas from the thoughts and writings of others, because studies often bring out the differences among hydrologic systems, and these differences make technology transfer difficult. Yet, in spite of the differences in hydrologic systems, similarities exist. And, just as these similarities exist in hydrologic systems, there are similarities in study design - regardless of the disciplines involved and regardless of whether the work is on a surface- or ground-water system.

Study design is a thinking process, just as are data analysis and interpretation. The thinking process begins by building a mental framework of the problem either by assembling the whole from the parts (inductive reasoning) or by evaluating how the parts operate by viewing the entire structure (deductive reasoning).

Inductive and deductive reasoning essentially stem from the writings of Sir Francis Bacon (1561-1626). A definition for both from Ghent (1966, p. 17-22) is:

\section{Inductive reasoning:}

"Individual data or concepts are assembled, and from a consideration of them we reach a general proposition, model, or hypothesis of the system. The structure of the whole is determined (estimated) by analyzing its particular parts."

Deductive reasoning:

"We deduce from a hypothesis (even guesswork), using associated knowledge, that certain results or conditions will follow. And, 
from these conditions, other conditions perhaps more complex) will follow. One infers the existence of the likelihood of particular events from a knowledge of the structure of the whole."

These two approaches to thinking are truly unifying concepts. Depending upon the problem to be solved and what is known about the problem, either of these approaches, or a combination of both can be used. An illustration patterned from Ghent (1966) shows how inductive and deductive reasoning can be tied together in problem solving (fig. 1).

The overlapping squares between A and B illustrate the concepts of how functions and observations are meshed. The more information and thought about the system, the better the anticipated observations begin to fit with the actual observations (measurements) that are made. Or, if the concept of the framework of the system is in error, the anticipated observations will diverge from actual observations, and we must alter our thinking. Much of the problem solving in our lives revolves around inductive and deductive reasoning, and it is useful to organize our thoughts and observations along discrete lines. Ross (1966, p. 15-17) said it well when he wrote:

"In organizing our attack on a new question, we choose between the operational methods-analysis and synthesis. If we decide that separating a larger system into its component parts will give us clues to our dilemma, we have chosen the avenue of analysis; if we decide that we will get the desired information by adding together various building blocks and combining them into a more highly organized structure, we have chosen synthesis. In a general way, analysis corresponds to deduction; synthesis to induction. In actual practice, both analysis and synthesis involve long programs of many steps, and each step is accomplished by the spiral of inductive-deductive reasoning."

Remember that inductive and deductive reasoning are unifying concepts, and their effective use does not come easily. Reasoning is the foundation of design and thus design truly becomes an intellectual activity. More will be said about inductive and deductive reasoning as the steps of study design are expanded.

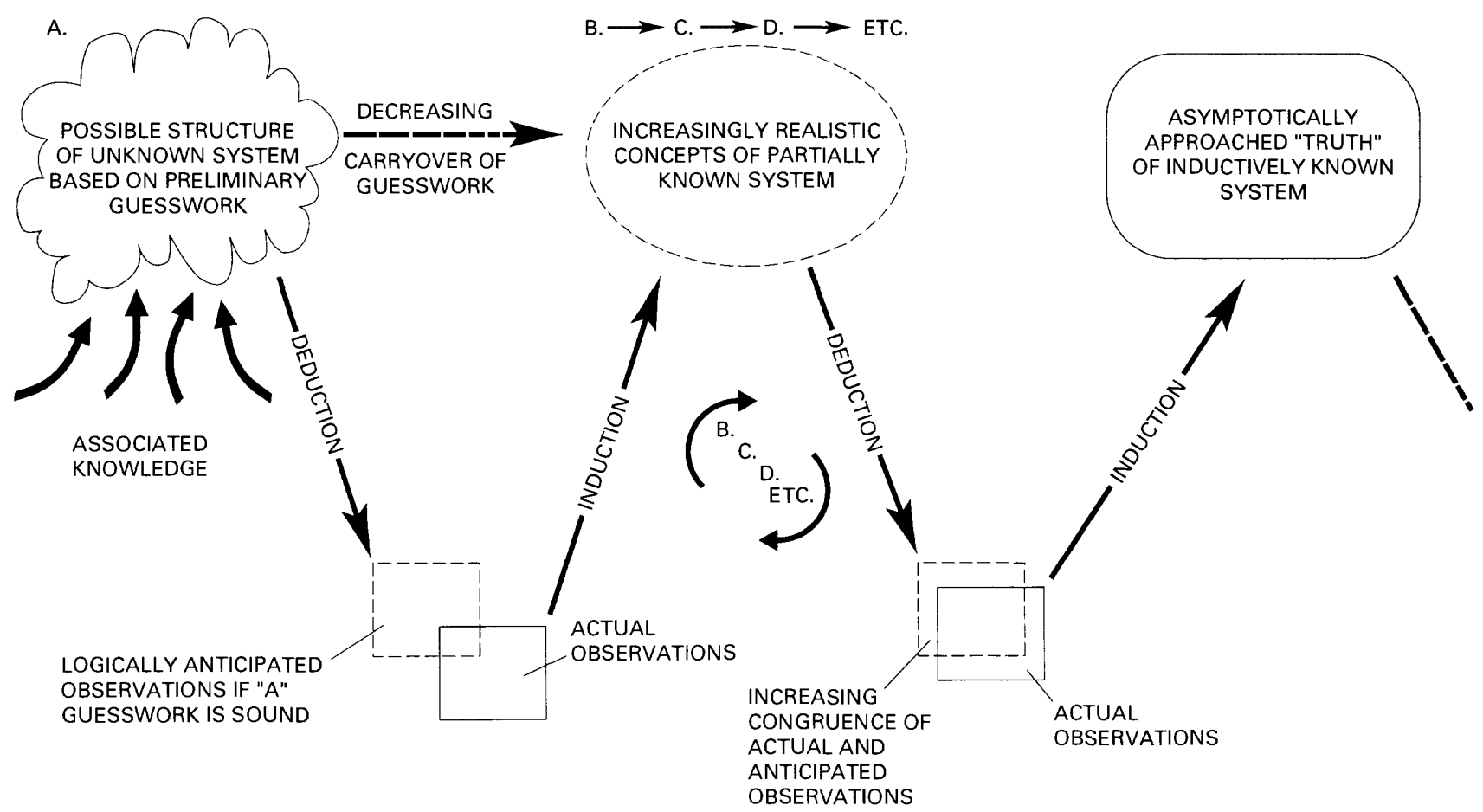

Figure 1. Problem solving using inductive and deductive reasoning (modified from Ghent, 1966, p. 15-17). 


\section{Prediction, Proof, Understanding, and the Scientific Method}

Prediction is a role of science. In the 1960 's, we came to realize that there is only one planet on which to live-therefore, the emphasis is to predict or prove what would happen if we did this or that. The cause and effect relation requires that we understand, not just document, what is happening. The tool we use to predict, prove, and understand is the scientific method.

At the most elementary levels, scientific investigation and the scientific method are taught with emphasis directed towards scientific "proof." Daily, we read where science has "proven" this or that. Actually, the scientific method is designed to disprove rather than to prove. Can an experiment be designed to prove something? The number of possibilities is too great; too many things would have to be disproved before something could be proved. When scientific experiments reveal that a particular thing happens, what is revealed is the outcome of a particular experiment. Seldom, if ever, are we told the experimental design used to arrive at the reported results. The point here is that most scientific investigations disprove rather than prove, and that the experimental design that is used is crucial to the result. If we keep an open mind and continuously question our hypothesis, the information always comes closer to results that advance the understanding of hydrologic events.

The major tool of science, the scientific method, leads to understanding. Understanding is a necessary condition for prediction, and without understanding, prediction is fantasy. For this reason, models of hydrologic systems not only must be understood, but must be verified by actual observations. And to be useful, such models, as well as other scientific experiments, must be multi-faceted.

Chamberlin (1897) emphasized that a single hypothesis was insufficient to explain many phenomena in nature. He felt that too often when scientists made a single hypothesis, they became strongly attached to it even when it was incorrect. Some highlights of Chamberlin's paper follow:

"There are two fundamental modes of study. The one is an attempt to follow by close imitation the processes of previous thinkers and to acquire the results of their investigations by memorizing. It is study of a merely secondary, imitative, or acquisitive nature. In the other, the effort is to think independently, or at least individually. It is primary or creative study. The endeavor is to discover new truth or to make a new combination of truth or at least to develop by one's own effort, an individualized assemblage of truth. The endeavor is to think for one's self, whether the thinking lies wholly in the fields of previous thought or not. It is not necessary to this mode of study that the subject matter should be new. Old material may be reworked. But it is essential that the process of thought and its results be individual and independent, not the mere following of previous lines of thought ending in predetermined results. The demonstration of a problem in Euclid precisely as laid down is an illustration of the former, the demonstration of the same proposition by a method of one's own or in a manner distinctively individual is an illustration of the latter, both lying entirely within the realm of the known and old."

"Too often a theory is promptly born and evidence hunted up to fit it afterward. Laudable as the effort at explanation is in its proper place, it is an almost certain source of confusion and error when it runs before a serious inquiry into the phenomenon itself. A strenuous endeavor to find out precisely what the phenomenon really is should take the lead and crowd back the question, commendable at a later stage, 'How can this be so?' First the full facts, then the interpretation thereof, is the normal order."

"An infelicity also seems to attend the use of the method with young students. It is far easier and apparently in general, more interesting for those of limited training and maturity to accept a simple interpretation or a single theory and to give it wide application, than to recognize several concurrent factors and to evaluate these as the true elucidation often requires. Recalling again for illustration the problem of the Great Lake basins, it is more to the immature taste to be taught that these were scooped out by the mighty power of the great glaciers than to be urged to conceive of three or more great agencies working successively in part, and simultaneously in part, and to endeavor to estimate the fraction of the total results which was accomplished by each of these agencies. The complex and quantitative do not fascinate the young student as they do the veteran investigator."

Like Chamberlin, Platt (1964) was a proponent of the multiple hypothesis and carried Chamberlin's thinking a step further emphasizing that science disproves not proves. Here are some highlights from Platt's paper:

"In its separate elements, strong inference is just the simple and old fashioned method of inductive inference that goes back to Francis Bacon. The 
steps are familiar to every college student and are practiced, off and on, by every scientist. The difference comes in their systematic application. Strong inference consists of applying the following steps to every problem in science, formally, explicitly, and regularly":

1. Devising alternative hypotheses;

2. Devising a crucial experiment (or several of them) with alternative possible outcomes, each of which will as nearly as possible, exclude one or more of the hypotheses;

3. Carrying out the experiment so as to get a clean result; and

4. Recycling the procedure, making subhypotheses to refine the possibilities that remain, and so on.

$* * *$

"To paraphrase an old saying, beware of the person of one method or one instrument, either experimental or theoretical. This person tends to become method-oriented rather than problemoriented. The problem-oriented person is at least reaching freely toward what is most important. Strong inference redirects a person to problemorientation, but it requires the person to be repeatedly willing to put aside the last methods and teach oneself new ones."

"In numerous areas that are called science, the investigators have come to like our habitual ways and our studies that can be continued indefinitely. Some investigators measure, define, compute, analyze, but do not exclude. And this is not the way to use the mind most effectively, or to make the fastest progress in solving scientific questions."

"One severe, but useful private test that removes the necessity for third-person criticism, because it is a test that anyone can learn to carry with him for use as needed, is from the Baconian 'exclusion', renamed here as 'The Question.' Obviously, it should be applied as much to one's own thinking as to others. It consists of asking in your own mind on hearing any scientific explanation or theory put forward, 'But sir, what experiment could disprove your hypotheses?'; or, on hearing a scientific experiment described, 'But sir, what hypotheses does your experiment disprove?'
$* * *$

"It is not true that all science is equal, or that one cannot justly compare the effectiveness of scientists and investigators by any method other than a mutual-recommendation system. The person to watch, the person to put your money on, is not the person who wants to make 'a survey' or a 'more detailed study', but the person with the notebook, the person with the alternative hypotheses and the crucial experiments, the person who knows how to answer your question of disproof and is already working on it."

The papers by Chamberlin (1897) and Platt (1964) are paramount to clear thinking in study design and should be read annually by everyone involved in scientific investigations. Chamberlin (1897) believed that too often a theory is born and only evidence that supported it was gathered. This was not an unusual phenomena in his day, and unfortunately, is not rare enough today. Chamberlin urged the collection of "full facts" before the interpretation. As Chamberlin pointed out, an event may be the result of several factors working together or independently. The experimental design must consider the number of things impinging on the hydrologic system being studied. We must always consider this point.

Platt's (1964) idea was to test one or more hypotheses by experimental design and to keep experimenting until there were no more hypotheses to test. While perhaps a somewhat ideal approach, the thought process suggested by Platt is nevertheless correct. Platt was concerned about "one method" approaches and "method oriented" approaches. Such approaches are greatly limited and may regress rather than progress thinking and problem solving. Never mind the "better mousetrap" approach; design the experiment to solve the problem, not to advertise a new technique or to modify older ones. Platt was concerned more about disproving hypotheses than proving them, which parallels the earlier statements about science not proving hypotheses, but in contrast, disproving hypotheses.

\section{A PROBLEM-ANALYSIS APPROACH}

Problem analysis, like research, is an intellectual activity. One analysis approach is first to define the problem, then to define the type of study that is needed, and finally to clarify your thoughts by thinking and writing. 


\section{Defining the Problem}

Defining the problem for your study is a difficult but important process. Perhaps the most useful technique in predicting the success or failure of proposed studies is to ask the study chiefs to define the problem they have proposed to solve. If the chiefs cannot do so briefly and clearly, they have serious problems ahead. The odds do not favor a successful study, either in the production of useful data and conclusions, or in a clear, well-written report. There is little difference between study success and deriving a mathematical equation. You cannot complete either successfully unless you know the objectives-that is, unless the problem is defined.

Problem definition is the task of the study chief. The chief must define the problem and must live with the definitions throughout the life of the study. That is why a clear definition of the problem is necessary before a study design can take place.

A study chief should never rely upon a supervisor to define the problem and should not rely upon members of the cooperating or supporting agency to define the problem. Remember you alone will be held responsible for its success or failure. Consequently, you alone should define the study.

Problem definition can take on several forms. As an example, say the USGS is to undertake a so-called baseline water-quality study of Spring Creek. Such a title tells little. Water quality is that part of hydrology that is concerned with the kinds of things in water. Is everything that is in the waters of Spring Creek going to be measured? Obviously not, and to be successful, some non-water-quality variables need to be measured as well. The problem we are to solve and the scope of this problem will be determined, among other things, by the present and anticipated use of Spring Creek water; the size, type, and land uses of the drainage; and other factors that impinge upon the water quality of Spring Creek including non-water-quality influences. In fact, more non-water-quality factors might have an influence upon your decision of what to sample in Spring Creek than the water-quality factors.

You may believe that increased salinity resulting from irrigation-return water or increasing chromium concentrations resulting from a metal-plating plant are the water-quality problems in Spring Creek. If increased salinity is a problem, the study chief would want to measure specific conductance and the concentrations of the dissolved salts in solution. With the metal-plating effluent, chromium and other metal concentrations as well as $\mathrm{pH}$ would be some of the measurements to make.
Problem definition for the above examples would be very simple- "The problem in Spring Creek is increased salinity resulting from the irrigation of ' $n$ ' acres above the city of $\mathrm{X}$-ville. We propose to collect water samples for the determination of $\mathrm{Na}, \mathrm{Cl}, \mathrm{SO}_{4}$ and so forth, at a frequency of $\mathrm{X}, \mathrm{Y}$, and $\mathrm{Z}$." While very simplified, the study chief has defined the problem and laid a cornerstone. The problem in Spring Creek is, from our analysis, an increase of salinity resulting from irrigation return water. Focus your efforts on the problem.

As your study progresses, you may uncover other phenomena and may wish to consider them. Indeed, you may have to modify your definitions. But if you have done your homework, you will be able to stay with the game plan; that the problem in Spring Creek is salinity. You must measure the concentration of $\mathrm{Na}, \mathrm{Cl}, \mathrm{SO}_{4}$ and so-forth at a frequency of $\mathrm{X}, \mathrm{Y}$, and Z. As simple as your problem definition may be, it is essential that the problem be defined early in your study or study planning. Your definition must be clear and as accurate as possible.

Before planning the attack on the Spring Creek problem, you need to obtain a receipt for your efforts. You, as a study chief, are to define the problem. Now provide your supervisor with a written definition of the problem. Writing down the problem provides you the opportunity to be precise and your supervisor the opportunity to study your problem definition. The problem definition is a statement of your convictions. Let those who disagree step forward and express their objections in writing as you did.

Defining the problem is the first and sometimes most difficult step in the long, arduous journey of a hydrologic study. It is a step that must be taken carefully and with deliberation; the definition is based on all available information about the stability of the tobe-trodden ground. The goal of a written problem definition is to provide evidence that the study chief is certain of the direction, and that the supervisor understands what you have proposed. This is only the first step in your study design; be certain that there is no misunderstanding between the responsible parties.

After the problem is defined, and only when it is defined, can you proceed with the design of the study. If the problem is not defined, further progress is futile because you have nothing on which to attach your design.

\section{Defining the Study}

Once the problem is defined, you need to define the type of study you will manage. It may seem unnec- 
essary at this point to define the study type, but there are good reasons to do so. When you have everything in order, you are going to write a study planning report-a sort of contract between you and your supervisor. A part of this contract will be a description of the complexity of the study you plan to undertake. Also, at this early time in the study design, it is useful to place things into boxes-that is, into categories that can be combined into the whole.

Most studies can be placed into the broad categories of reconnaissance, monitoring, and interpretative. Mixing them only leads to confusion. Definitions of the three study types are as follows:

Reconnaissance: A reconnaissance study is concerned with determining the distribution and abundance of things (data). It is an overview type of study that, if carefully planned, will show what is there, where it is, and how much of it is present. A well-planned reconnaissance study is the key to the design of a more advanced study such as an interpretative study. Reconnaissance studies can be made without going into the field if sufficient data about the system being studied are available. Only limited interpretation can be made from the reconnaissance-study data.

Monitoring: A monitoring study is concerned with particular measurements exceeding predetermined values. An effective monitoring study can result only after the reconnaissance study has defined the distribution of things.

Interpretative: An interpretative study is concerned both with the abundance and distribution of things and with those processes that influence the distribution and abundance of things. An interpretative study generally is best carried out after a reconnaissance study of the system. Process and assessment studies are truly interpretative studies.

Placing your study into one of these categories does not mean the study is locked into that category forever. The categories should be a way to view your study - a way to place your study in perspective. Do not try to make an interpretative study out of a condition where available data, the state of the art, or the budget will permit only a reconnaissance study. In contrast, do not limit yourself to a reconnaissance study when the wherewithal and other conditions, including consulting talent, are available for an interpretative study. Finally, do not propose a monitoring study unless sufficient reconnaissance data to define the distribution of things in the system are available. To do so will leave your design and any results open to much criticism.

\section{Thinking and Writing}

In this section, two inseparable activities, thinking and writing, are brought together. There is a great deal of mental activity and anguish to study design. Successful studies and study chiefs require a great deal of writing to supplement, as well as to support, their thought. At one time or another in our lives we were told, or at least believed, that the writing phase of a study began when the data have been collected. This is fiction. You start writing almost as soon as you start thinking about your study.

Most of the thoughts you write down will turn out to be of little or no value to the design of your study; if 10 to 20 percent of them are useful, consider yourself fortunate. Remember that non-useful ideas can lead to useful ideas, and at this point, you cannot distinguish between them. You can be certain that you need all the ideas you can get. Write down all your ideas related to your study as you think of them, and be thankful you thought of them regardless of when or where or how valuable they may be. You can always throw away a written thought: you cannot always recapture a forgotten one.

Keep in mind that most successful study chiefs did not begin successfully — each has one or more studies that they would just as soon forget, studies that were poorly designed. More could be added here, but you now know what you must do. Your expertise on how to do it will improve with time.

Always keep in mind that there is no upper limit to the goals you may strive for in your study. You have restrictions in the form of money, time, and talent, but many excellent studies have been carried out under conditions where resources were extremely limited. Keep in mind also that there is really no upper limit to the quality you can build into your study. There is, however, a lower limit for study quality, and both you and your supervisor know what it is. Plan to build quality into your study from the standpoint of obtaining a clean result insofar as solving the defined problem is concerned.

Remember that your study is your responsibility. Your supervisor is more interested in your solutions than your problems. And, after all, you are paid for coming up with solutions, not transmitting problems.

\section{THE FRAMEWORK OF THE STUDY}

The study chief needs to ask a few questions. Your answers to these questions will tailor the approaches you use. Remember, you need to think before doing. 


\section{Some Preilminary Questions}

Soon, as a study chief, you will determine the types of data to be collected, determine the frequency of collection, put the study design together, and begin to write the report. These are difficult tasks, and you will want to be certain that each step is accounted for and, most importantly, that the study meets your expectations. Now is the time to be certain of your direction. If you have defined the problem and the study to your satisfaction and to the satisfaction of your peers and supervisor, you have crossed the first and one of the most difficult hurdles. At this point, you have given a great deal of thought to your study and should have some plan for its execution. This is now the turning point of the study.

Study expectation is a most important morale factor and leads directly to study success. If you undertake a study that is beyond your experience or capability, you may be frustrated, but you can call for assistance to help you over the highest hurdles. If you have any skill at all, you can produce an acceptable product. Moreover, your technical skill will grow under such conditions. In contrast, if you undertake or design a study that is well below your capabilities, you will become frustrated soon after the study begins. There is no way you can call for help, except perhaps to be replaced as study chief, an action that creates a management problem as well as a study delay. Consequently, it is important that you design your study to stretch your imagination and that the study fulfills your expectations. Successful study chiefs insist on designing their own study from start to finish to ensure that these goals are met.

With these thoughts in mind, pause for a moment and ask some questions. You may not have the answers to all these questions now, but you will want to weave the questions and your answers into your study design. Here are some of the questions; hopefully, you can think of others:

1. Upon completion of the study, will your knowledge of the hydrologic system be significantly greater than before the study began? Consider this question seriously. The study may not be necessary.

2. Is sufficient manpower (including talent) and money available to do the study as you envision it? Here again, your answer to this question will seriously affect the success of your study.

3. Will you be able to design and carry out the study so as to collect the maximum amount of useful information for the least amount of expended effort? Are time and other constraints too restrictive? Perhaps it is a bit premature for this question, but it needs your attention.

Give these three questions some serious thought at this time. If the answers are "no," discuss them with your supervisor and peers and make some adjustments so that you can answer each question with a "yes."

One other factor should have your attention and thought at this time-it is the report you will prepare to present your findings. It is not too early to think about the type of report you will prepare and how you will present the data. After all, the report is your ultimate goal of transforming data into information.

\section{What Information is Avallable}

There are not many places on this planet where someone has not collected some data. In the hydrologic field, your organization or the USGS has often been there. If not, other Federal or State agencies may have obtained some hydrologic information be it streamflow, sediment, chemical, or biological data. Ground-water data are frequently available from the files of the State Engineer or State Geologist as well as from files and reports of the USGS.

Most of these available data may not have been collected in a manner useful for your study. Typically, the data will have been collected for another purpose and will not fit into your plan; that is, you cannot use the data to solve your defined problem. In many instances, the data will not be in a useful form. However, if available, such data can be extremely useful in the design of your experiment. They can provide insight on what to expect in the hydrologic system that you are to study, and they can provide information about concentration ranges of constituents and measurement variability. In some instances, there may be sufficient information to satisfy a part of an interpretative study that requires reconnaissance data.

Do not limit your search for existing information to just those parameters of immediate interest. Information related to the use of the system by humans, releases from upstream impoundments, and land use in the drainage are all useful pieces of information for the design of your study. As an example, several years ago, a USGS office was asked to design a water-quality study in a section of a river that flowed through a heavily used section of a national park. There were no physical or chemical data available for the river section to be studied, but a USGS benchmark station located in the upper drainage of the river above the study section provided information about major chemical constituents, discharge, sediment, and water temperature. At a 
site some 15 miles downstream from the park boundary, discharge and some water temperature information were available. Although not directly useful for the study reach, these data provided information about when the high and low flows and high water temperatures would occur. Information about visitor use of the park was made available by the U.S. National Park Service. By reviewing all available antecedent datastreamflow, water temperature, and visitor use-a sampling program was designed that insured that samples would be collected during extreme hydrologic events, as well as when stress by heavy visitor use was placed on the river section. The chemical data from the upstream benchmark provided information about the quality of the river before it flowed through the main park area; thus, the benchmark station served as a control site.

Now, you will not always be as fortunate as in the example just given. Sometimes, little, if any, data are available, and data do not meet your needs. You can sometimes circumvent this problem by reviewing information available from tributary streams or adjacent drainages, but you must be cautious in transferring data from one place to another. Sometimes it is safer to synthesize and think about the system and how it ought to work, rather than try to use data from a system that is entirely different.

\section{RELATING HYDROLOGIC PROPERTIES}

Few events in the hydrologic environment are completely independent of one another. Most properties that the hydrologist measures are influenced by each other. In some ways, this fact makes your task difficult, but also it makes your task much more interesting and provides the opportunity of synthesizing expected results of one constituent from the known results of another constituent. To do so, however, requires a great deal of effort and thought and is perhaps the most difficult assignment for a new study chief to complete. Once used, however, synthesizing expected results becomes a routine and an effective way of thinking. The following example may illustrate how to relate measurements.

You know, or should know, that in the absence of human-induced inputs, the dissolved-solids concentration in a stream is inversely related to stream discharge. In other words, a simple dilution effect governs the concentration of dissolved solids in a stream. Were you to plot dissolved solids as a function of discharge, the graph would look something like figure 2.

Now, you do not know the slope of the line nor do you have any exact values. At this time, having the slope or concentration values is not essential because you are designing your experiment. Later, especially if the dissolved-solids concentration is to be a part of your study - that is, part of the problem-you will want to collect information that will describe the above regression with some accuracy.

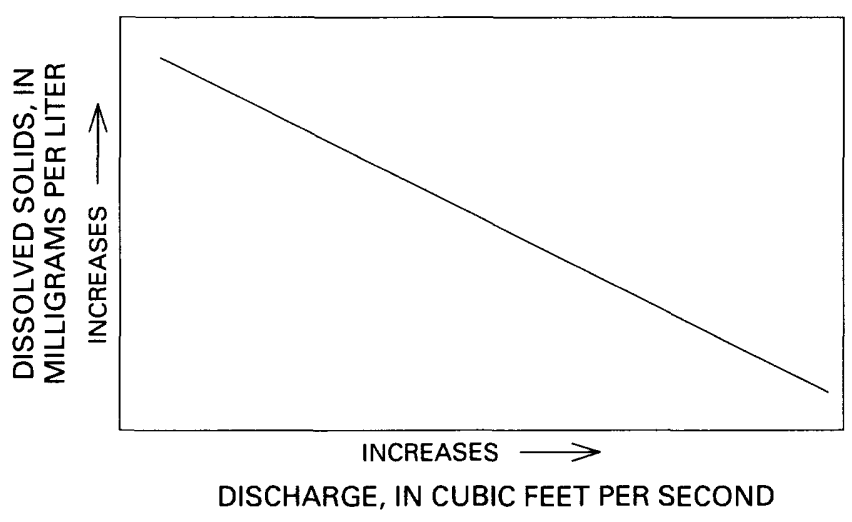

Figure 2. An example of the inverse relation between dissolved solids and discharge in the absence of humaninduced influences.

The next step is to plot a hydrograph of the stream. You can obtain such information from the annual USGS data reports. A simple hydrograph such as that shown in figure 3 will provide you with the expected variation in discharge.

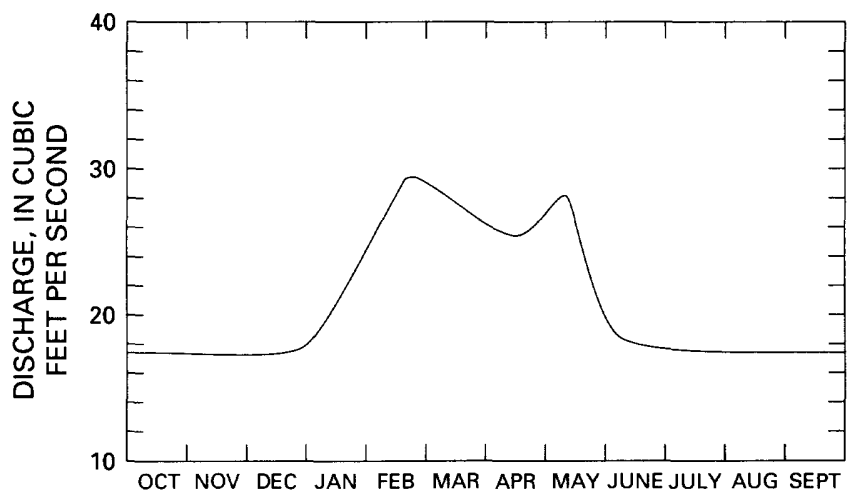

Figure 3. An example hydrograph of the variation of discharge with time.

From the hydrograph you can see that discharge in October, November, December, June, July, August, and September remains somewhat constant. The greatest variation takes place between January and May. Several things are thus apparent if you are to describe the discharge-dissolved solids regression. They are, among others: 
1. There should be little difference in the dissolvedsolids concentration from October to late January and June through September assuming no human-caused influence. Minimal sampling during these time periods should describe the discharge-dissolved solids relation.

2. More frequent sampling for the dissolved-solids concentration will be needed from January to May because this is the period of rapid changes in discharge, and hence rapid changes in the dissolved-solids concentration.

The discharge-dissolved solids relation is simple, but clearly illustrates the theme of relating hydrologic properties. In this example, you know the discharge profile and the expected relation between discharge and dissolved solids. Without a single dissolved-solids value you determined which periods to sample. If the hydrograph is complex, or varies greatly from measuring station to measuring station, you may wish to make a flow-duration hydrograph for a clearer idea of the discharge pattern. You commonly can obtain, by visual inspection of a hydrograph, all the information you will need for study planning.

In addition to the discharge-dissolved solids relation, you may wish to look at the major ions that influence dissolved solids. Knowing something about the lithology of the area will be very helpful here, but if chemical data are available, all the better. Computing the milliequivalent values for these ions will tell you the water types (Hem, 1985, p. 56). Be certain, if data are available, to look at the water type for both high and low discharge because the water type can change as a function of runoff intensity and duration. Examine also the water types in a downstream direction to see if changes result from tributary inflow. Finally, determine the dissolved-solids and specific-conductance relations to the major ions. The graph will look something like figure 4 .

Here again, you may not have much firm data to work with, but the point is to consider the relation as a guide to thinking and planning.

You have now read about discharge-time relations and discharge-constituent relations, as well as the briefly mentioned specific conductance-constituent relations. In some instances, plotting constituentconstituent relations is useful and should be considered if the data are available.

Many constituent concentrations are not completely discharge related. Wastewater spills and other human-caused events may result in extremely erratic concentration patterns. In addition, many trace elements and organic materials are sorbed on sediment particles. Thus, suspended sediment acts as the trans- porting mechanism. In a sense, the movement of material is discharge related because movement of sediment is a function of stream velocity. However, when the discharge decreases, the sediment is deposited, often in an erratic or patchy manner. Increased discharge results in the sediment, and therefore, the sorbed material, to again be in transport, and concentrations of both sediment and sorbed material may be erratic for a time. You may find that the maximum suspended-sediment concentrations occur during decreasing discharge.

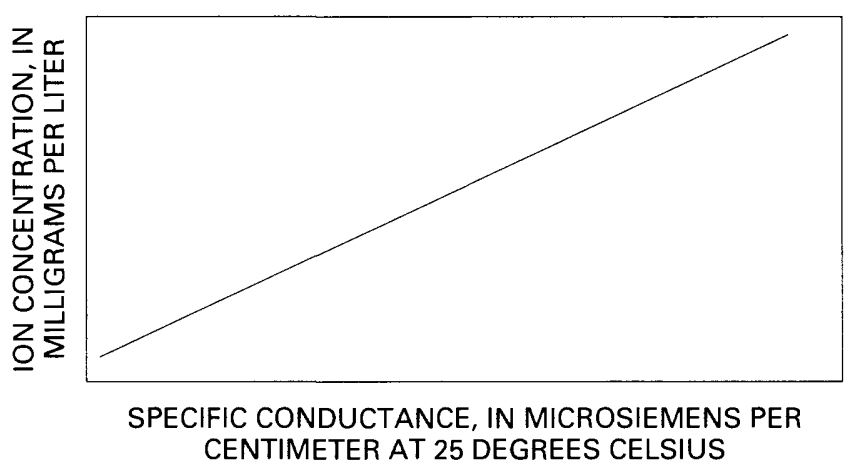

Figure 4. An example of ion concentration related to specific conductance.

Biological material is both discharge dependent and discharge independent depending upon the material and the magnitude of the discharge. For example, many stream invertebrates drift in the water; this is either a behavioral or obligate event and is discharge independent. In contrast, during floods when bed material is moving along the channel bottom, many stream invertebrates, as well as much of the attached algae, move because of the flow velocity and scouring action of bedload moving along the stream channel bottom.

It is important to consider the adsorption and related characteristics of chemical constituents. Plant nutrients, such as nitrogen and phosphorus, vary depending upon the species. Nitrate is highly soluble, whereas phosphorus sorbs readily to sediments. Thus, the transport mechanisms are quite different. Unless you consider the behavior and transport mechanisms of the constituents you are studying, you will have difficulty in interpreting your findings.

How do you handle seemingly nonflow-related events where the material input may be independent of the discharge? How do you use nonflow-related events as the framework for your ideas? Consider, for example, the constituent-distribution patterns in figure 5.

Constituent-distribution patterns will vary in rivers and streams, but the sketches A-D (fig 5) will take care of our needs. Sketch A represents a system, or part of a system, where the constituents have a steady input 

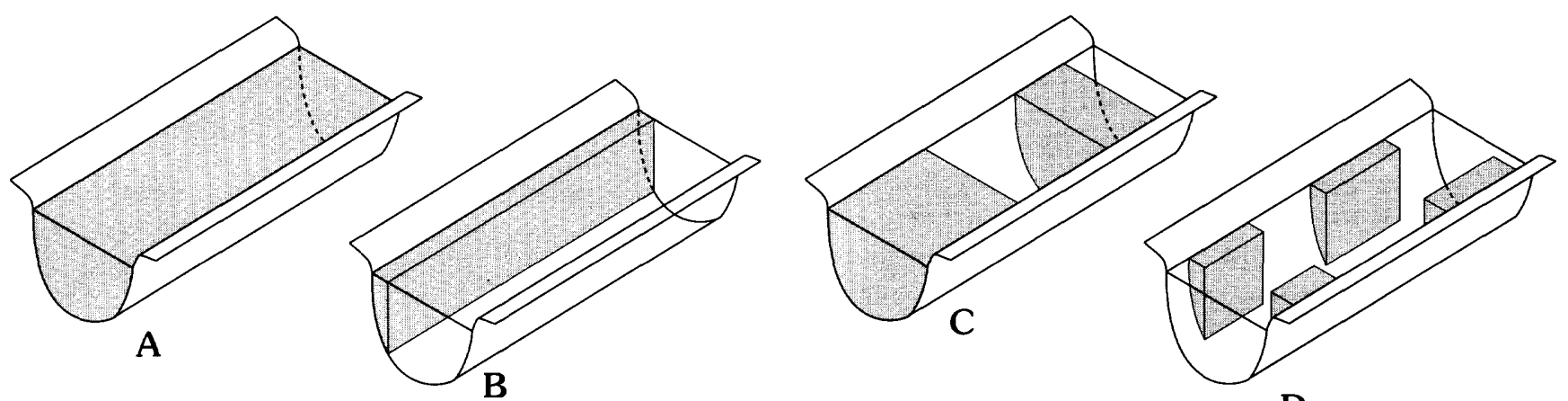

D

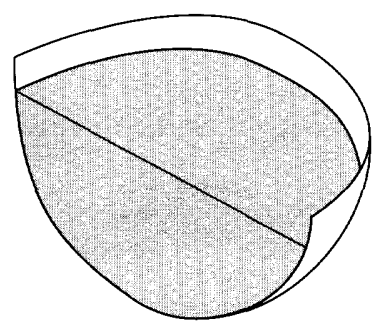

E

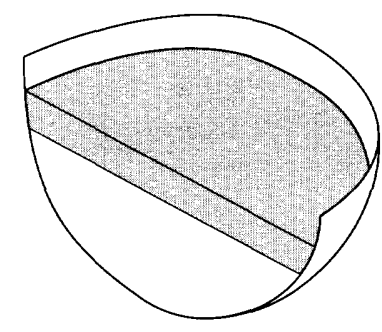

$\mathrm{F}$

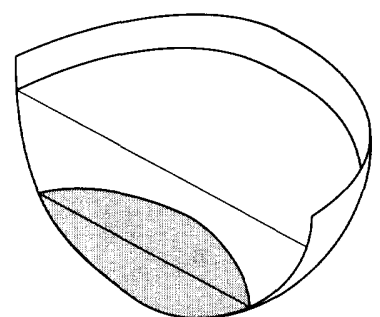

G

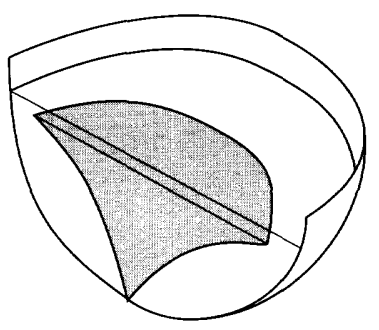

$\mathbf{H}$
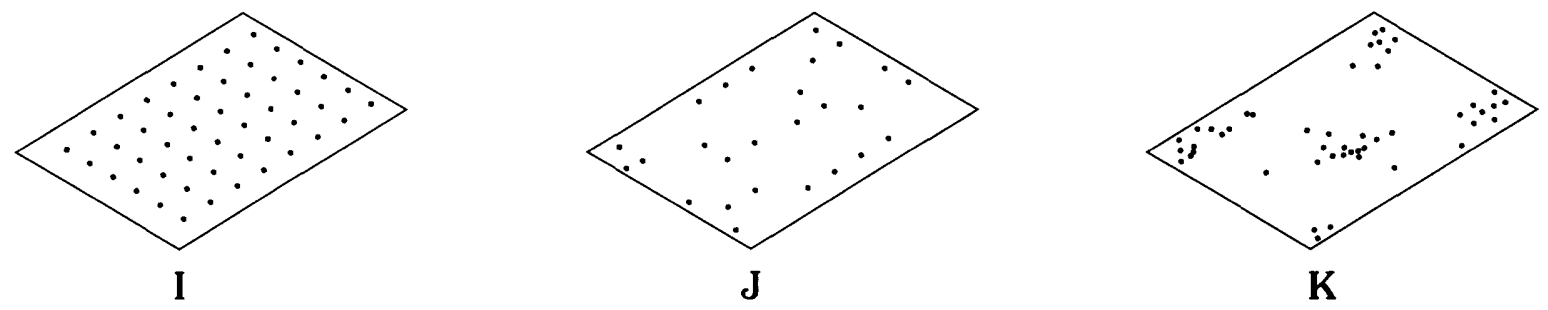

Figure 5. Examples of possible constituent-distribution patterns in hydrologic systems.

and are well mixed. This type of system is the simplest from the standpoint of sample-site selection and frequency of sample collection. Unfortunately (or perhaps fortunately), a system with steady input and complete mixing is rare in nature. Sketch B represents a system having steady input and poor mixing, which is not unusual in nature for short sections of streams.

Sketch $C$ represents a system where the material is well mixed, but the input is erratic. Finally, Sketch D represents a system where the material flowing into the stream has an erratic input and is poorly mixed. Conditions represented by sketches $C$ and $D$ are not unusual in many rivers and streams, especially over long reaches where tributary inflows and diversions occur.
Human-induced releases of material produce the greatest interest because they are dramatic, and, of course, can be unnatural to the system. However, uptake and release of material by biological activity also may be dramatic and result in an erratic input pattern. Biological uptake of minerals and other nutrients by plants is commonly rapid and of a high magnitude during the spring growing season. Releases of these materials are obviously greatest later in the season when the plants die.

In contrast to long-lived rooted plants, periphyton growing on a stream or lake bottom, or phytoplankton in a lake or reservoir, may become abundant and die off several times in the spring and summer, each event results in the uptake and release of material. Some potential distribution patterns for phytoplankton and 
other materials in lakes are shown in sketches $\mathrm{E}$ to $\mathrm{H}$ in figure 5 .

Sketch $G$ represents a system in which the greatest distribution is near the bottom. Now, we could easily relate sketch $G$ to organisms that live on the bottom of lakes and reservoirs, but the distribution is equally applicable to sinking phytoplankton cells, as well as some chemical constituents that are most concentrated in the water that lies just above the lake bottom.

Sketch $\mathrm{H}$ shows a relatively sparse constituentdistribution pattern at the surface, followed by a subsurface maximum. This distribution pattern is an extension of sketch $\mathrm{F}$ and illustrates a typical phytoplankton abundance curve, as well as a dissolvedoxygen curve.

Sketches I, J, and K (fig. 5) represent the distribution patterns of benthic materials and organisms, but with some thought, could be extended to materials and organisms in the water column as well. These sketches represent distribution patterns that we can describe from a statistical standpoint. We view them as things on a plane, but the principles involved also will be applicable from a three-dimensional profile.

Sketch I represents a uniform distribution pattern. While few things are uniformly distributed in nature, a uniform distribution is possible over short time periods or within small areas (Elliott, 1977). Very small suspended particles such as clays and solids in solution may follow a uniform distribution pattern.

Sketch $\mathrm{J}$ represents a random distribution. The random distribution simply means that no pattern is present; there is an equal chance of occupying any space in an area. Sketch $\mathrm{K}$ is a clustered or contiguous distribution. This is the distribution pattern that described organism communities. The contiguous distribution is therefore a very important distribution in nature.

The goal here is to guide your thinking about how things are distributed in nature. Most of us have some pretty clear ideas on distribution patterns, but too often neglect this knowledge when we design a study. Too often, we try to sample everything all the time, a clear indication that we have made study design a mechanical rather than an intellectual activity.

Let's relate hydrologic findings to our study through examples. You will have to relate them to your own study problems. As the examples are described, you will see how important it is to have defined the problem at the beginning of the study.

\section{Exampie 1-Stream or River}

Suppose that the problem of a study is to determine the influence of domestic waste discharge to a receiving stream. Suppose further (for the sake of seasonal variations and other complexities) that the study is in a resort area where summer and winter sports prevail; that is, summer hiking, fishing, water skiing, and winter snow skiing.

Because the waste is of human origin, you can begin by constructing a visitor or population curve as a function of season (fig. 6).

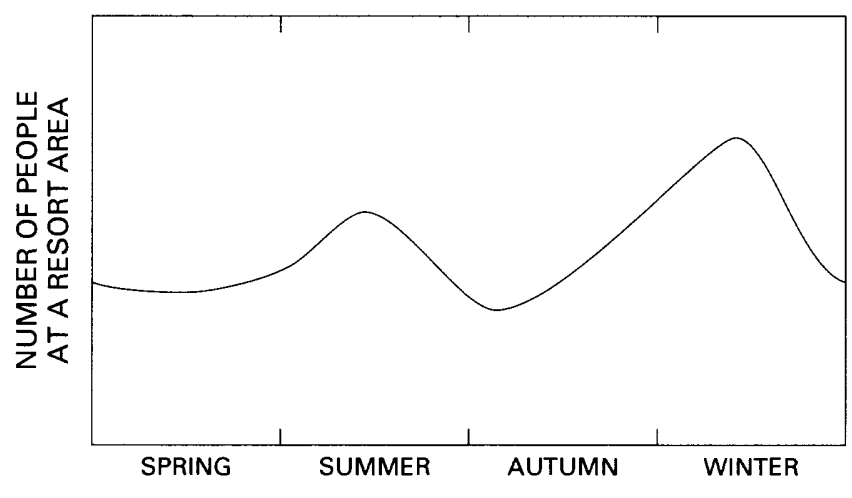

Figure 6. An example of the distribution of people at a resort area by seasons of the year.

The population or visitor curve also may be used to provide information about the effluent discharge to the stream. Obviously, the more people in the area, the greater the effluent discharge.

Again, you do not need to have actual values. Assume more people use the area in the winter, because snow skiing has a more concentrating effect on the water quality than summer hiking, fishing, or water skiing. If the graph is correct, the greatest periods of sewage loading will be in the summer and winter. Now consider the controls on the sewage. Plant growth and production in the stream will begin in the spring. Rooted or riparian vegetation will reach maximum size during the summer. Thereafter, they will cease growing but take up additional nutrients and other material for their metabolic needs. Attached algae (periphyton) will reach maximum population in early summer, then die and grow again throughout the summer. An example simulating a plant growth curve is shown in figure 7.

The expected relations (fig. 7) are not going to be accurate under all conditions because you do not know or understand all of the circumstances at this time. However, the relations are reasonable portrayals of what to expect. Again, no values are on the ordinate of the graph. You do not need them at this time, for you 

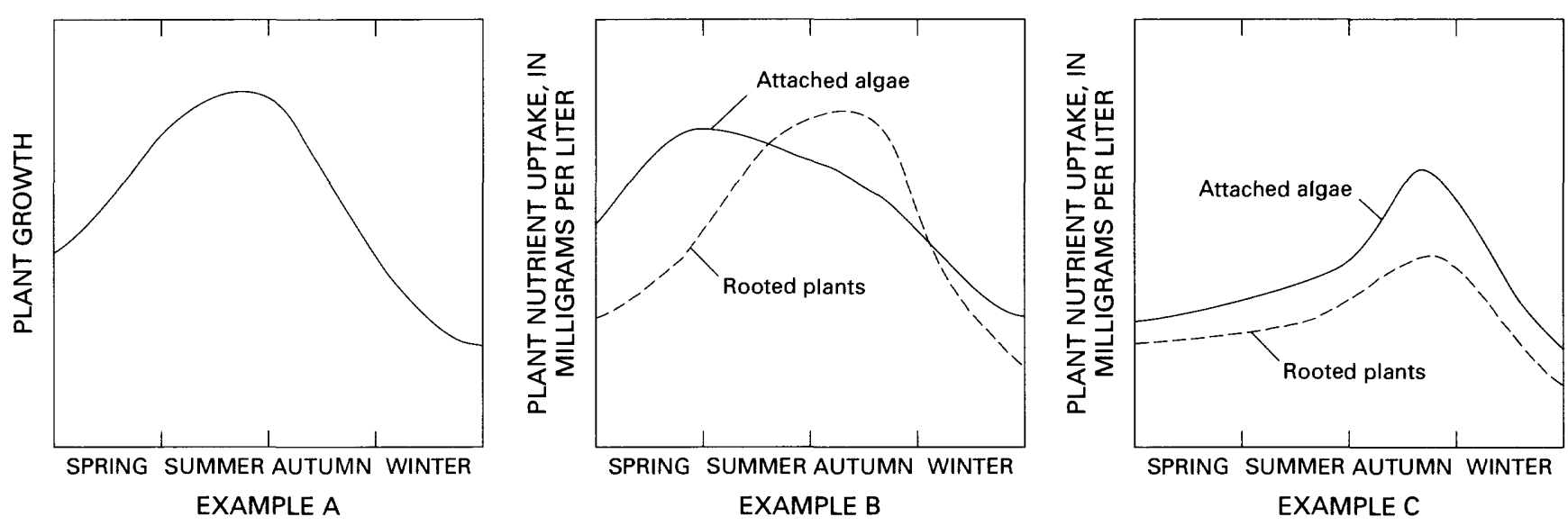

Figure 7. Examples of plant growth-production curves by seasons of the year.

are designing a study that will provide measurements to show these concentrations.

Because the study area includes a ski area, seasonal water-temperature changes are extreme and will have an important role in controlling the bacterial decomposition of the sewage. Water temperature, therefore, must certainly be considered in your study design. A possible seasonal water-temperature graph would look like figure 8 .

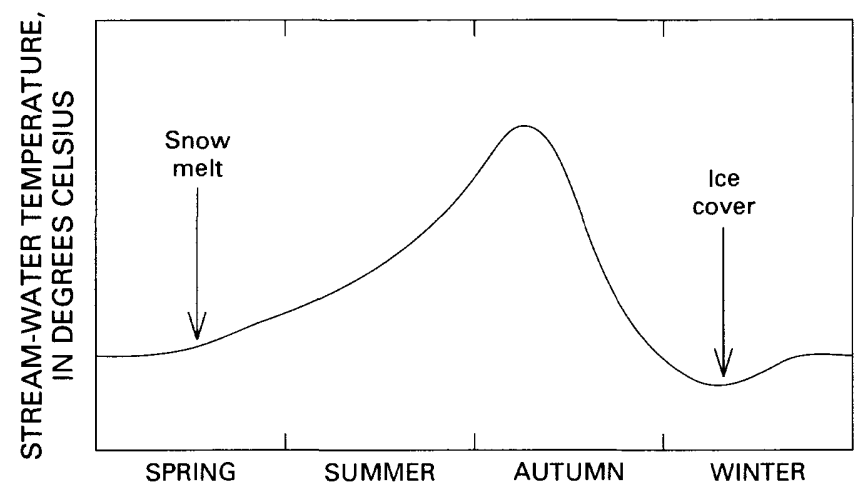

Figure 8. An example of water temperature by seasons of the year.

Temperature will have its greatest influence on the decomposition rate of the sewage and the biological oxygen demand. Thus, you should describe the possible seasonal decomposition rates as a function of season and distance downstream from the sewage outfall (fig. 9).

This graph (fig. 9) may have a dual purpose. If you should decide that the measurement of intestinal or sewage-indicating bacteria should be a part of your study, you could relate the bacterial distribution to this graph.

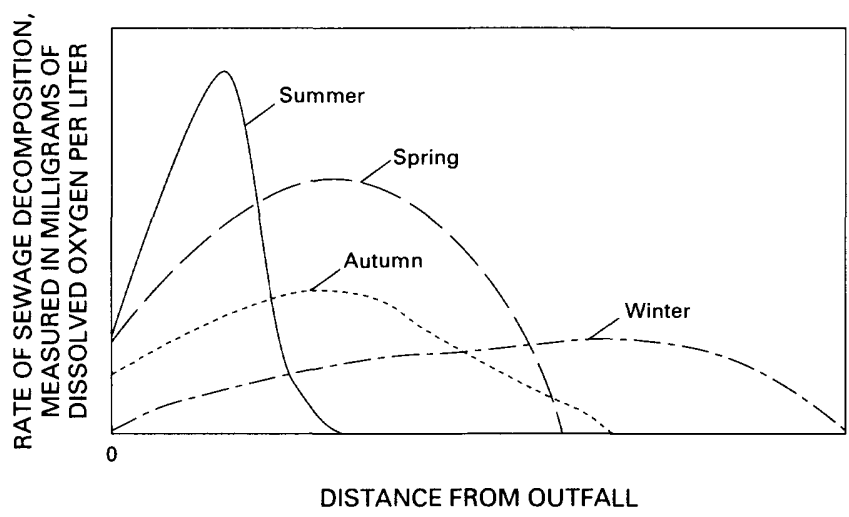

Figure 9. An example of the rate of sewage decomposition at various distances from the sewage outfall.

The discussion of stream discharge was left to near the end of the example to emphasize other factors. However, placing it last does not minimize its importance. Let's sketch an expected discharge hydrograph (fig. 10). At this time, the stream discharge hydrograph should be compared to the population or visitor curve (fig. 6). Note that the highest stream discharge occurs during a period of low visitor use and hence low wastewater discharges. Highest wastewater discharges occur at low-flow periods. You should carefully consider these factors in the design of your study.

Earlier, it was stated that trace metals may be important to the study. You now know, or should know, that most trace metals and indeed many organic constituents are sorbed on sediment particles. Thus, you need to sample the sediment. For your present purpose, you 
can use your discharge curve to estimate periods of highest suspended-sediment concentrations.

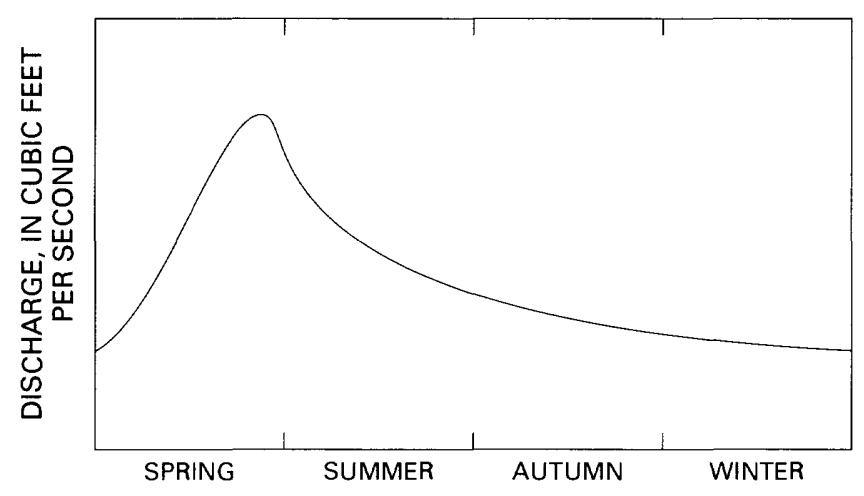

Figure 10. An example of a discharge hydrograph.

Other factors could be considered, but you have enough examples to get started. Now put your ideas together in a family of combined curves as illustrated in figure 11.

Notice that these are relative curves-that is, the factors are related to the season and to each other. Also, the graphs have no numerical values because your interest here is in the ups and downs and the rates of going up or down, not the actual values. As an example, if you wish to know something of the trace metal transport in the stream, you will certainly need to sample in the spring during snowmelt and hence the period of highest sediment transport. If determining particulate (suspended) and dissolved organic matter is a part of your study objectives, you will need to sample near the outfall in the summer. However, perhaps farther downstream would be satisfactory in the winter because of reduced bacterial oxidation rates at low water temperatures. Certainly, if you wish to determine the stress on the system-that is, when the most adverse water-quality conditions will exist-then you will want to sample in the summer when discharge is decreasing but sewage-decomposition rate and water temperature are increasing. Winter also is critical because stream discharge is reduced and the stream may be ice covered, resulting in anaerobic conditions even though the temperature is low.

Without any data and with just some oldfashioned intuition, or inductive reasoning, you have derived a model of the system you are to study. You have the conceptual framework of the distribution and abundance of hydrologic factors and some of the processes involved. Most importantly, you have put your thoughts on paper in the form of a series of relation graphs. You have been forced to think, to review your thinking, and to discard factors that did not fit. You have done it all with a pencil, some paper, and some hard thought. There may be an easier way to do it, but there is no more effective way. Sampling everything and sampling all the time are poor approaches because you carefully defined your problem, you know what to sample and when to sample, which will eliminate the collection of the wrong kinds of data.

\section{Example 2-Lake or Reservoir}

The example given for a stream or river system should be sufficient to point out the ideas, as well as the need to relate data; however, an example for lakes and reservoirs also is in order. We will emphasize lakes, but will include a few words about reservoirs.

Lakes are depressions on the earth's surface and thus, act as depositories for many materials in the environment. The materials finding their way into lakes may be transported by the wind as well as by water. Once in the lake, part of the material will be there forever and some material will pass through the lake. Thus, lakes are, in part, recycling systems.

For example 2, suppose that your defined problem is to determine the enrichment, or if you prefer, eutrophic status of a particular lake (or reservoir). Now, this problem definition is broad; but, if you are familiar with the several schemes of lake classification, you will know that several measurements can be made to determine the degree of lake enrichment. Here is a partial list:

\section{Water temperature;}

2. Dissolved oxygen;

3. Phytoplankton composition, distribution, and density;

\section{Nitrogen and phosphorus concentrations; and}

5. Primary production.

There are other measurements you could make, but the above five will serve as examples. Let's begin.

No lake study would be complete, nor could really even begin, without a good understanding of the water-temperature profile. Water temperature is a controlling factor. If you know anything about the physical features of the lake you are to study, such as depth, area, and so forth, you should be able to sketch the expected seasonal temperature regime. Some expected thermal profiles for a classical temperatezone lake (fig. 12) will be our example.

These are not all of the possible profiles, because between winter and spring, and autumn and winter is an overturn period-often short lived-and the lake is homothermous; that is, the thermal profile is com- 


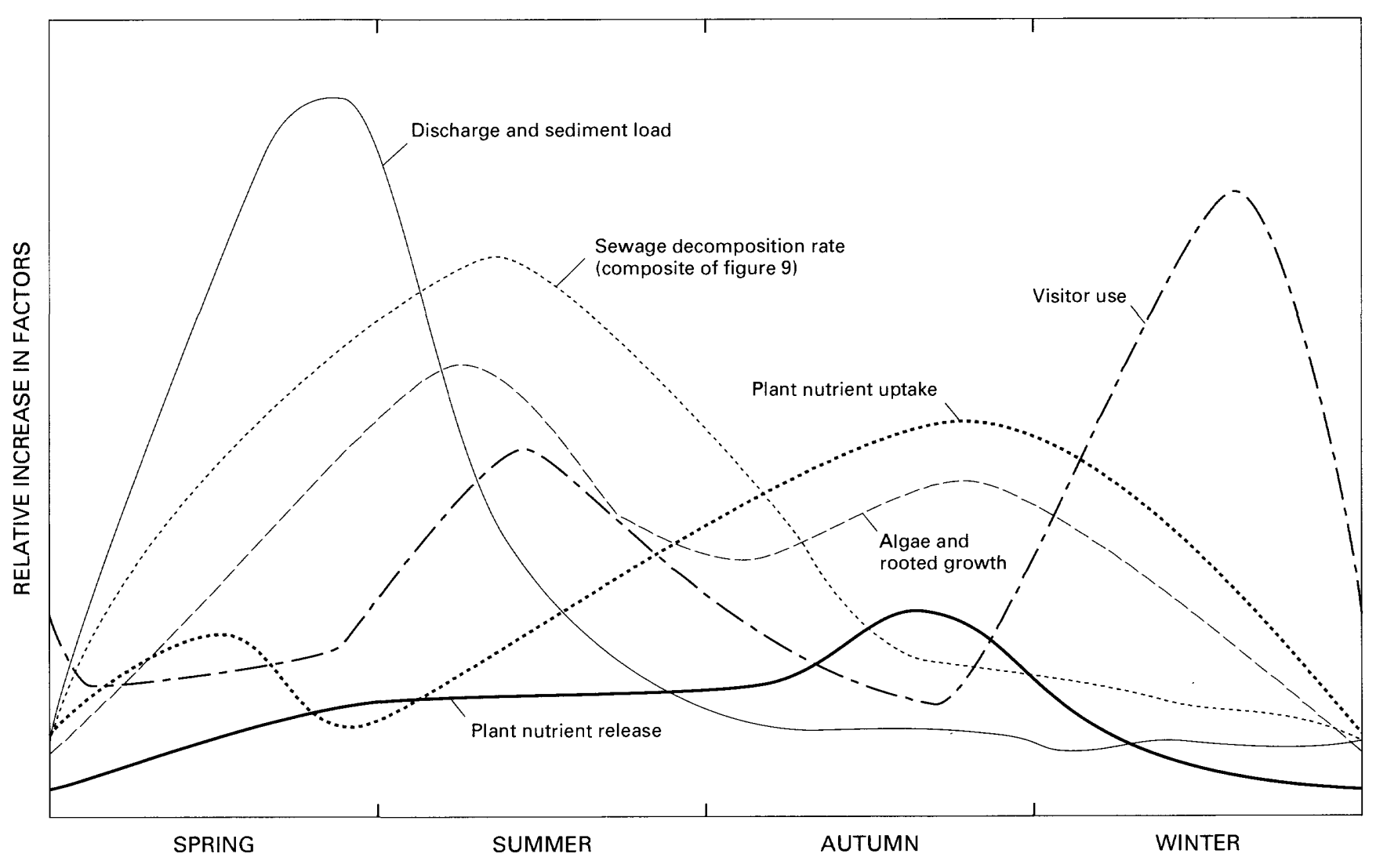

Figure 11. An example of different combined curves by seasons of the year.
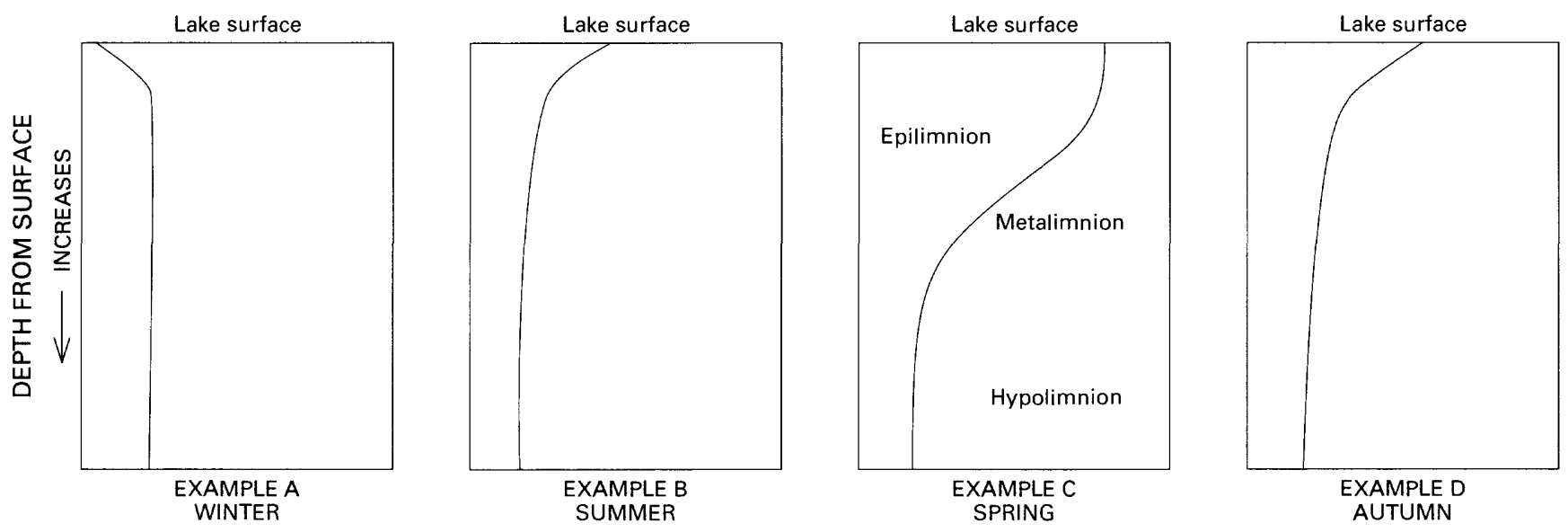

TEMPERATURE, IN DEGREES CELSIUS

Figure 12. Water-temperature profiles for a classical temperate-zone lake by seasons of the year. 
pletely vertical. This is an important time to sample for some constituents, such as major ions, trace elements, plant nutrients, and algae because there are no thermaldensity restrictions in the lake, and constituent stratification may not exist.

Although water temperature may not provide direct information about the enrichment status of a lake, the metalimnion acts as a mixing barrier and prevents re-oxygenation of the hypolimnion during the summer stratification period. Once the lake becomes thermally stratified, there is no way for any significant amount of dissolved oxygen to enter the deeper water from the lake surface. Unless you have some previous knowledge about the lake, you cannot predict the late summer dissolved oxygen resources in the hypolimnion. But you can sketch some possible dissolved oxygen curves for an enriched and an unenriched lake (fig. 13).

The two lines, solid and dashed, represent different types of lakes based on enrichment. The solid line represents an enriched lake; the dashed line represents an unenriched lake. Together the sketches provide insight into the several differences in dissolved oxygen concentrations that could occur between the two systems. The enriched lake will have relatively high phytoplankton production in the epilimnion, resulting in a pronounced subsurface dissolved-oxygen maximum. Also, the enriched lake will have less dissolved oxygen in the hypolimnion because bacterial oxidation of sinking phytoplankton cells utilizes dissolved oxygen. The result may be anoxic conditions as shown in the summer and autumn graphs (examples C and D, fig. 13). In contrast, your lake may be an unenriched system with only minor phytoplankton production, resulting in little photosynthetic oxygen production in the near-surface water and little dissolved oxygen uptake by bacterial respiration in the bottom water. At any rate, the dissolved oxygen measurements in your lake deserve your attention for they can provide you a great deal of relatively inexpensive information.

The determination of phytoplankton composition, distribution and density is paramount to the success of answering your defined problem. You will again have to guess at their distribution patterns, but with a little thought and literature review you can make a reasonable guess. At least you can portray the possibilities. An example of a classical phytoplanktonabundance profile is shown in figure 14 .

The important point to keep in mind is that high production occurs in the enriched system, whereas the unenriched system typically cannot support many blooms. For example, the unenriched system in figure 13 has a spring period of high algal production, or a spring "bloom." This bloom is mostly diatoms, but other blooms of a lesser magnitude and different algal types might occur later in the year. There simply are too many possible events that take place with regard to phytoplankton between an enriched and an unenriched lake to present all of the possibilities. Therefore, phytoplankton concentration isn't the hydrological factor to measure.

The number of cells per unit volume of water is only part of the story-just the census. You also need to know the composition of the cells-the species or
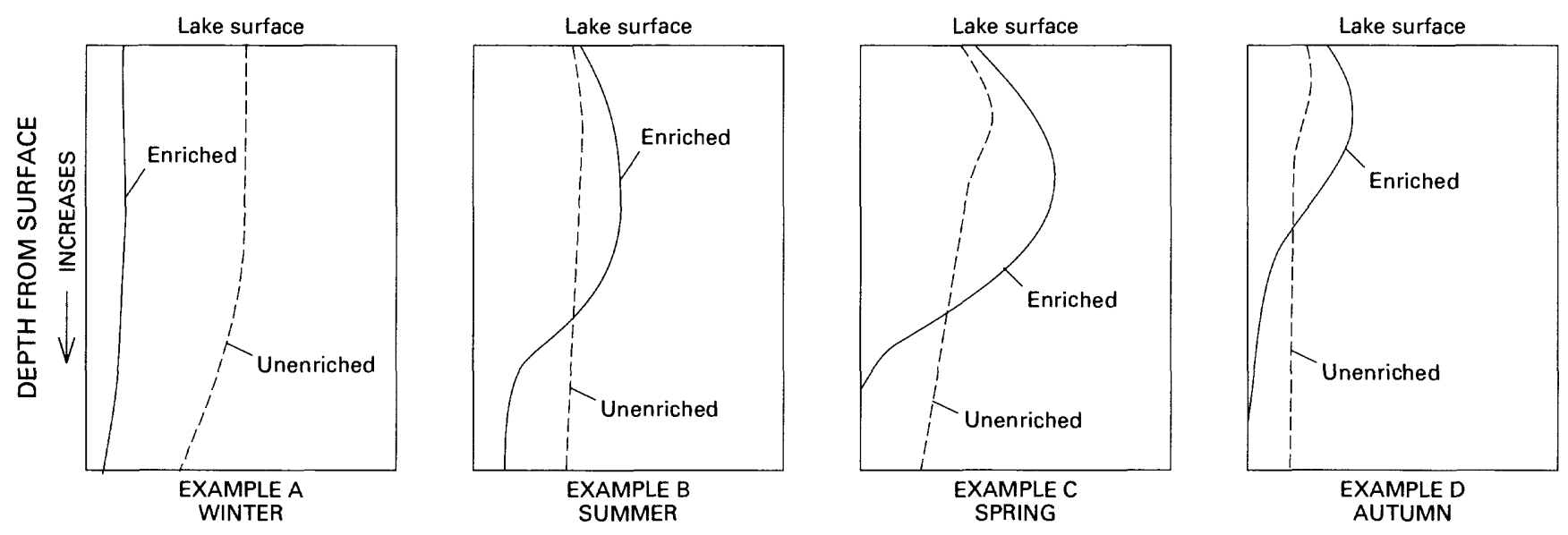

DISSOLVED OXYGEN, IN MILLIGRAMS PER LITER

Figure 13. Dissolved oxygen profiles for a classical temperate-zone lake by seasons of the year and degree of enrichment. 
types. Otherwise, you have just counted the number of people in the block; you don't know if they are whitecollar or blue-collar workers. You might expect from figure 14 , that the diatoms are not indicators of enrichment-they occur in both enriched and unenriched lakes. If you ignore a host of other complexities, the blue-green algae are often the dominant algae of enriched waters. Frequently blue-green species are indicators of excessive nutrients in lake systems. Thus, it is imperative that you know the seasonal species changes in phytoplankton and be aware that you may have to conduct rather frequent sampling.

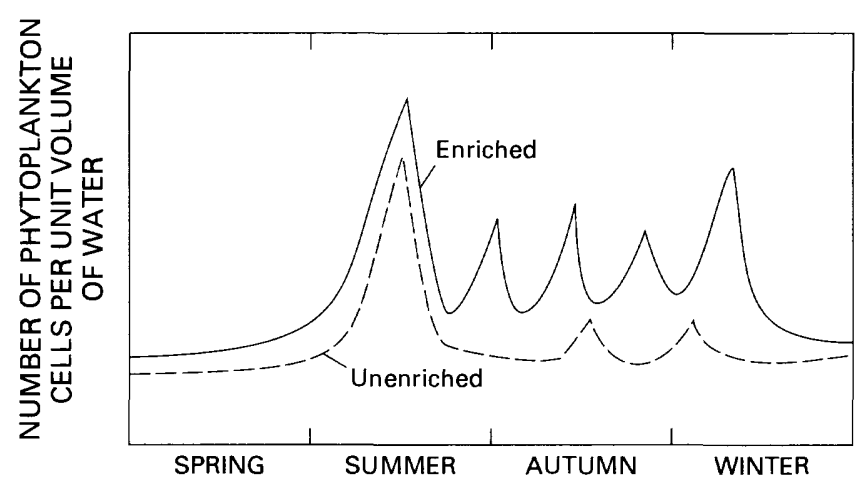

Figure 14. An example of a classical phytoplanktonabundance profile by seasons of the year.

The term "plant nutrients" has been mentioned a number of times, and the two plant (algal) nutrients that are likely to be growth-limiting in natural waters are nitrogen and phosphorus. To be sure, there are many other types of plant nutrients, including trace elements, but nitrogen and phosphorus, especially phosphorus, are the most likely to be growth-limiting in aquatic systems. At a minimum, you would want to measure nitrate, organic nitrogen, ammonia, and ortho- and total phosphorus. You could expect the amounts and distribution of nitrogen and phosphorous to be the inverse of phytoplankton concentration, at least during periods of phytoplankton bloom. To obtain an estimate of the total amount of nitrogen and phosphorous available to phytoplankton, you would make measurements in the lake during the winter when phytoplankton production is low, or perhaps during the spring overturn when the lake is homothermous and well-mixed.

Primary production, the amount of living material assimilated by plant cells (algae in this case), is an important measurement in classifying the enrichment status of lakes. The measurement of primary production is time consuming and thus expensive, and you will want to insure that this measurement pays its way. One way to help ensure that you make the primary production measurements at the time of maximum assimi- lation by the algae is to carefully review the dissolved oxygen and phytoplankton values. When these values begin to increase, you should plan to make primary production measurements. Expected primary production profiles would look something like that shown in figure 15.

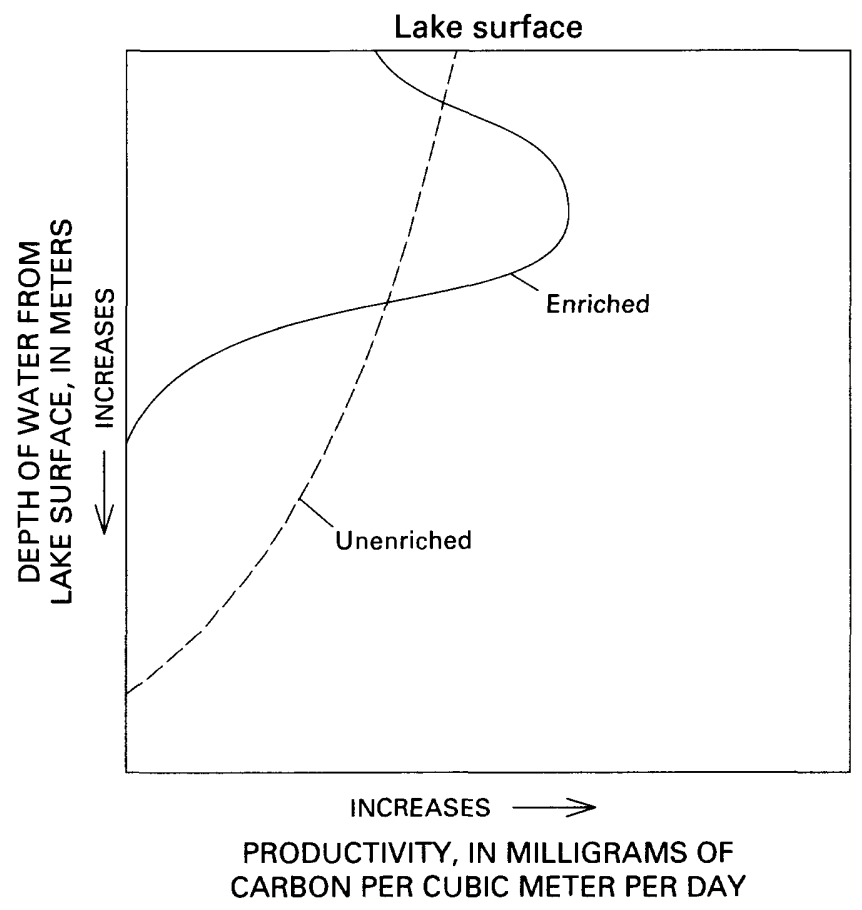

Figure 15. An example of primary-production profiles in a lake.

Stop now and try to gain some insight as to how these factors are related and put your thoughts on paper. A composite graph for unenriched and enriched systems would probably look like figure 16 .

Unless you are a limnologist, parts of this discussion seem complex. In reality, however, this discussion is no more complex than the example of the stream that received domestic waste; only the problem and the systems are different. You now have some idea as to what your minimum sampling and measurement program must be; and you will know when you must sample. As you progress with your study, you should look for signs that indicate that your sampling should be intensified or that it should be reduced. A rapid dissolved-oxygen decrease in the hypolimnion in the spring and summer and the presence of blue-green algae in the summer are indicators of stress conditions in lakes and reservoirs and may require more intensive sampling to define the conditions.

Compared to reservoirs, lakes are generally simple systems with relatively small drainage areas, sea- 

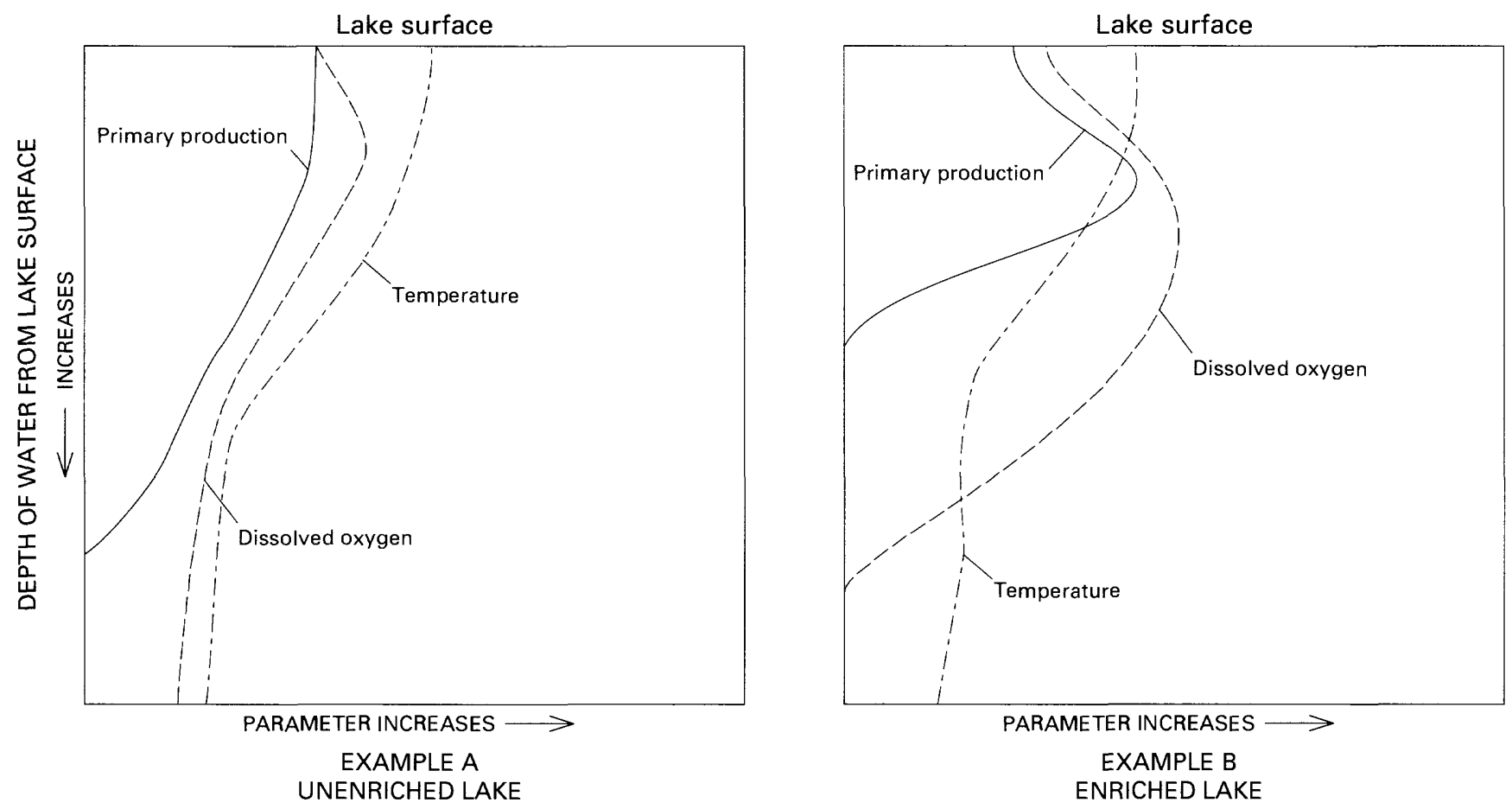

\section{CONSTITUENT CONCENTRATION}

Figure 16. An example of constituent concentration in $A$, an oxygen-unenriched lake and $B$, an oxygen-enriched lake during the summer.

sonal inflow and outflow regimes (sometimes no inflow or outflow), and, often, circular in form. Lakes also are old, and often their ecosystems are somewhat in equilibrium, except where humans have interfered. In contrast, reservoirs have large drainage areas (impounded rivers) and are elongated and young (few over 100 years of age). Because reservoirs are impounded rivers, reservoirs retain many of their river characteristics, but also possess some characteristics of lakes. Dams and their attendant reservoirs are built for specific purposes, and their management for those purposes alters the natural flow regime in the river channel downstream. Thus, not just the impounded part of the river changes when a dam is built, but also the river reach below the dam. Because flow regimes downstream from dams almost always are different than the normal seasonal flow regime, the river ecosystem is often in long-term disequilibrium. Impoundments affect river reaches in other ways below dams. In many reservoirs, the water is released from the hypolimnion, resulting in a constant cold-water river downstream from the dam. If the water is taken from the surface of the reservoir, the downstream water is often much warmer than historically had been the case. Reservoirs also become sediment and nutrient traps, starving the river downstream of both constituents.

In the impoundment itself, a different biota and water chemistry develops, and sediment accumulates. Tributaries entering a reservoir become drowned at their mouths, which causes sediment and other materials normally carried by the tributary to accumulate. Mixing behavior of water in reservoirs is often complex and depends greatly on the density (a function of temperature and salinity) of the incoming water.

Reservoirs are not the same as lakes; there are many differences that your sampling scheme should reflect. Keep in mind that rivers downstream from dams are different in many ways than rivers that have no impoundments. Two in-depth books on the subject of reservoirs are by Petts (1984), and Thornton, Kimmel, and Payne (1990), and sampling technology is covered by Wetzel and Likens (1991).

\section{DETERMINING WHAT TO MEASURE}

The study chief needs to determine the data requirements, and to decide whether a synoptic experiment is essential to the study. After these decisions, the study chief needs to decide which analytical technique 
to use for each constituent. We will examine the data requirements first.

\section{Arranging the Data Requirements}

You have made considerable progress at this point, provided that the relations diagrams of the last section have been carefully thought out. Thinking about and diagramming the relations of the elements that impinge upon the problem to be solved is extremely important because it focuses your attention on the important aspects of the problem, as well as provides a way of deciding what you need to sample. Mostly, gross categories of your study were examined in the last section, for example, sediments and sorbed trace elements. The examples did not specify which trace elements are of interest, nor if you should make a size analysis of the sediment, but now is the time to do so. Three concepts need to be considered.

First, do not lock into your mind, to the exclusion of all others, the constituent measurements you are going to make. Constituent selection and frequency of measurement are never-ending activities, much like every study is a learning process throughout life. Second, if you do add constituents or measurements, examine carefully their relations to time, other constituents, measurements, and so forth, as much as you did in "The Framework of the Study" section. A safe rule is not to add constituents or measurements unless you can justify a relation with the system being studied.

Third, make every constituent or measurement that you select pay its way; do not collect or measure something just because your study can afford it. If you have good reason to believe a constituent or measurement will be of no value in solving your problem, then do not include it. Also, beware of constituent "blocks" or group constituents (schedules) that laboratories offer. Such schedules were designed for a particular program or study. All the constituents in a particular schedule might not be useful for your study. Remember that you will be held responsible for the data you collect, and that the collection of unnecessary types of data is one of the most common maladies of study design. Excessive constituent selection, coupled with a poorly designed collection frequency, results in the expensive and serious problem of collecting a great many of the wrong kinds of data.

The easiest and most effective way to overview the types of data needed to help solve your problem is by constructing a data-requirement matrix. When you do this, you can list and then see at a glance what types of information you will need to solve a particular phase of your problem. For example, imagine that at least a part of the problem you are to solve is concerned with the water quality in a stream section that receives discharge from a metal-plating plant. An example of a data-requirement matrix constructed around the metalplating problem, with some possible constituents you may wish to measure, is shown in table 1.

The purpose of the matrix is to provide an overview of the types of data you will need to measure. Our data-requirement matrix (table 1) could easily be expanded and improved. Do not be afraid to expand your matrix or to reduce the number of constituents or measurements. Avoid the use of broad categories such as "trace elements." The use of broad categories will hinder your thinking; you must be specific from now on in your study design. List each constituent in a separate column.

The idea of preparing the data-requirement matrix is relatively simple and the mechanics simpler

Table 1. An example of a data-requirement matrix prepared for studying metal-plating plant discharge to a stream

[ $\mathrm{x}$, denotes data needed for this problem]

\begin{tabular}{|c|c|c|c|c|c|c|c|c|}
\hline \multirow[b]{2}{*}{ Problem to be studied } & \multicolumn{8}{|c|}{ Data needed } \\
\hline & Chromium & Zinc & Copper & $\mathrm{pH}$ & $\begin{array}{c}\text { Major-ion } \\
\text { dissoived } \\
\text { constituents }\end{array}$ & $\begin{array}{c}\text { Stream } \\
\text { discharge }\end{array}$ & $\begin{array}{c}\text { Suspended } \\
\text { sediment }\end{array}$ & $\begin{array}{c}\text { Bed } \\
\text { material }\end{array}$ \\
\hline Type of water released & $\bar{x}$ & $\mathrm{x}$ & $\mathrm{x}$ & $\mathrm{x}$ & & $x$ & & \\
\hline Water-type classification & & & & & $\mathrm{x}$ & $x$ & & \\
\hline Transport of materials & & & & & & $\mathrm{x}$ & $\mathrm{x}$ & $\mathrm{x}$ \\
\hline $\begin{array}{l}\text { Concentration of sorbed } \\
\text { materials }\end{array}$ & & & & & & $\mathrm{x}$ & $\mathrm{x}$ & $\mathrm{x}$ \\
\hline Effluent release & $\mathrm{x}$ & $\mathrm{x}$ & $\mathrm{x}$ & $\mathbf{x}$ & & $\mathrm{x}$ & $\mathrm{x}$ & \\
\hline
\end{tabular}


yet. What is difficult and must be done without any shortcuts is the thinking. Exactly like the example of the relations graphs presented in "The Framework of the Study" section, you must think, erase, add, and think some more. Do not pass on anything unless you can justify its existence and, as said before, make every constituent or measurement pay its own way. Freeloading data will hinder your thinking and later your analysis.

Once you have completed your data-requirement matrix, set it aside for a few days and then review it again and make any necessary changes. Keep thinking about the content of the data-requirement matrix and remember the following:

1. The data-requirement matrix is an extension of your relations graphs.

2. Expand your data-requirement matrix to the limit. Include all the constituents you expect to measure but make each constituent pay its way. Whenever possible, eliminate a constituent.

3. A data-requirement matrix requires a good deal of thought. Once completed, it requires additional thought to ensure it is true and complete. You will never be completely satisfied with your data-requirement matrix. One way to test the validity of the data-requirement matrix early in the study is to perform a synoptic experiment on part or the entire hydrologic system you are studying.

\section{Synoptic Experiments}

The term synoptic refers to a snapshot of something at a brief interval in time. An example is a television weather map that shows the weather across the United States for a given day. In the field of hydrology, synoptic experiments are used to obtain information over a portion of a hydrologic system in a short time period. To do this, people are positioned at predetermined sites and, at selected predetermined times, make measurements or collect samples. This process is continued at prescribed time intervals. Synoptic experiments on flowing or impounded waters are expensive and typically require many people to conduct them successfully, especially if the experiment extends over a 24-hour period and covers large areas of a river or lake. The cost of sample analysis also is an important consideration. Thus, synoptic experiments require welltrained personnel and careful planning of logistics. The first priority is to consider the times that the samples will be collected or to designate some other variables that signify when sample collection should begin.
In impounded waters, the depth of sample collection is important as well as the time. In flowing waters, depthintegrated sampling is often used, and consistency of equipment and procedure is extremely important.

Regardless of the logistical problems involved, synoptic sampling is an excellent method for obtaining an understanding of a river or lake system over a short time period. Furthermore, synoptic sampling is a most effective reconnaissance method, and should be used more frequently at the beginning of studies (Taylor and Averett, 1991), because synoptic sampling allows you to put your data in a spatial-by-temporal context.

\section{Some Miscelianeous Thoughts on Constituents}

In the design of every study, the question arises as to which analytical technique, which instrument, or which type of preanalysis treatment to use for a particular constituent. There are many ways to make measurements, many instruments to use, and several ways to prepare or preserve samples for analysis. All that can be said here is to use the most modern (state of the art) technique that is approved. If your water samples are shipped to a laboratory for analysis, be certain that you have followed the pre-analysis treatment recommendations. If you make on-site measurements, be certain that your instruments are properly calibrated and in good working order. Finally, follow established procedures. Do not use outdated techniques just because you understand them. All techniques must, of course, be referenced in your study planning report. Most importantly, you, the study chief, should be up to date on the latest techniques in your field.

It is not unusual to find someone who designs a study so that many hydrologic factors are measured at the beginning of the study, and then fewer and less frequent measurements are made. This "shotgun" approach often gets wide acceptance by study chiefs and in some instances is a necessary technique, but many studies designed in this manner fail to provide a first class product, a clean result. The reason is not because of too much data, but because of too little thought.

Thinking about the measurements you are going to make, thinking about why you are going to make them, and justifying all the data you plan to obtain leads to problem solving. Measuring everything and letting the concentration of a particular constituent be your guide in deciding if you are going to continue to collect data leads to number gathering.

Review your data-requirement matrix again, and consider effects of factors such as length of daylight (or 
darkness), thundershowers, floods, changes in suspended sediment, and extreme low flows due to water diversion or drought. Consider also the phases of the constituents. You may not be able to budget (time and money) sufficiently to cover all factors, but you should at least be aware of those your study design cannot cover.

Typically, our work regarding the quality of surface water concerns the measurement and understanding of the decomposition of organic and inorganic compounds. Algae, tree leaves, and other detritus are always decomposing in streams and lakes. We measure their decomposition products as dissolved organic carbon, nitrogen, phosphorus, and a host of other constituents. Pesticides applied to the land ultimately decompose or change structure to various metabolites; these, too, we measure. The point is that as we target specific things to measure, we must also plan to measure their by-products and metabolites.

\section{HOW MUCH-THE FREQUENCY OF SAMPLING}

In "Determining What to Measure," the need to plan is emphasized. Once you decide how and what you are going to measure, you continue planning when to measure and sample. Remember, you cannot make measurements or collect samples all the time, so be sure that each measurement and sample aids your understanding.

\section{How Often}

The frequency of sample collection governs to a great extent your budget and your allotment of human resources, including your own efforts in data collection. Moreover, the frequency of sampling determines whether you will have enough or too much data when you are through. Much of the study success and your ability to interpret your data is tied directly to your sample-frequency schedule.

You doubtless have some idea of the frequency of sample collection-some thoughts at least. If you have defined your problem and have thought about the distribution and abundance of components of the hydrologic system, you can probably come up with a reasonably good sampling frequency schedule. You might improve upon your intuitive feelings about how many samples to collect and when to collect them by reading the next section.

Nothing is mutually exclusive in study design; everything ties to that which came before and that which will follow. Sample frequency is tied to the places you will sample (stations or sites)-the subject of the "Where to Sample" section. The following list, incomplete as it is, has some things to consider in designing the frequency-of-collection phase of your study.

1. Types of hydrologic, biological, and chemical constituents to be measured: Are the constituents conservative or nonconservative? Are they sorbed to solid particles? If, for example, you are interested in the movement of pesticides, you will want to sample more frequently during the period(s) of sediment transport, and less frequently during low flow. If one of the constituents to be measured is dissolved oxygen, you may need to consider making diel (night and day) measurements because dissolved oxygen is strongly influenced by photosynthetic activity, which in turn is influenced by light and darkness.

2. Expected seasonal and temporal changes: Seasonal and temporal changes can result from changes in flow, storms with attendant runoff, rising and falling water temperatures, changes in biological growth, and so forth. Groundwater quality may change after intensive pumping, and the ionic composition of surface water may change after an extensive period of runoff. Be aware of, and consider seasonal and temporal changes. Remember, for example, that autumn leaf fall may add large amounts of organic material as well as manganese to streams, even though the discharge is low.

3. Influence of human-caused inputs: Now is a good time to refer back to the section "Relating Hydrologic Properties." You should have some idea at this point as to human-caused inputs. If they vary greatly, you will have to increase your sample frequency if you wish to describe their distribution and abundance with any degree of accuracy.

4. The within-versus between-sample variance: If the within-sample variances are widespread, you may have to use a stratified sampling approach (Elliott, 1977) or a systematic sample approach (Gilbert, 1987). The determination of the variance of the constituents typically requires an increased sample-collection frequency. Remember, you may need to collect replicate samples; and the collection of the replicate samples needs to be considered during this phase of your study. 
5. Data interpretation: Always keep in mind that you or someone will have to interpret the data you collect; someone will have to tell a story with your findings. Data-collection frequency ties directly to successful data interpretation. This does not mean that you must collect a great deal of data; it does mean you must collect the data at the correct time. Whenever you decide to collect some information at a given time, ask yourself if you will interpret it.

These are just some common-sense guidelines to follow. You can add others. In fact, the expected budget, distance to- and between sampling sites, available human resources, and so forth will affect the frequency of your sample collection. But do not let these constraints reduce your frequency of sampling to the point where you end up with a nonuseful amount of data. It is much better to restrict your area of study or the scope of your study if nonhydrologic constraints such as budget or human resources force a reduction in your frequency of sampling.

A final and most important note is due here. You must now start thinking about how you plan to analyze and present the data in your report. If you plan some statistical evaluations of your data, then you must use statistically valid methods. That is, you must employ a statistical strategy in your sample collection, and you must collect a large enough number of samples to ensure that your degrees of freedom are sufficient so that you may test the significance of your data.

\section{Some Statistical Tools}

Many hydrologic events, especially biological events, are stochastic. What happens today, the concentration you just measured or the event you just observed, may or may not happen again in the same fashion or at the same concentration. Although there is order in hydrologic events, often a very fine order, things tend to happen around a set of values rather than at a single value. If we report the chloride concentration at a site, at a particular time, as $12 \mathrm{mg} / \mathrm{L}$ (milligrams per liter), we are giving an exact value. But if we know something about the distribution and abundance of chloride, we know that $12 \mathrm{mg} / \mathrm{L}$ was the concentration only at the time the sample was collected. Had the sample been collected earlier in the day, later in the day, or earlier or later in the week, the concentration could be higher or lower than $12 \mathrm{mg} / \mathrm{L}$. With the concentration changing, we expect a central tendency or probable value instead of a single exact value.

Usually, the expected value is the sample mean or median. Care needs to be taken here, for although the mean value lies in the center of normally distributed data, it may never be representative of any real values. And, often the extreme values may be more important, depending of course on the defined problem. But the mean can be useful and gives us a great deal of information if there are fiducial- or confidence limitsaround it. The confidence limits placed around the mean are at some probability level. The 95-percent confidence limit, for example, is the probability that 95 percent of the time (based on our sample values), the chloride concentration would not be higher or lower than a particular range from the mean value. It indicates that there is one chance out of 20 ( 5 chances out of 100 ) that the confidence limits placed around the mean would be exceeded by a given chloride value. Using the 99-percent confidence limit, the probability range becomes much larger, because any chloride value outside the 99-percent confidence limit has only a 1 in 100 chance of occurring.

When the mean and its confidence limits are determined from a set of hydrologic data, a statistical model is being applied to the data. This model, like all models, has some assumptions. The principal assumptions are that the individual data points are scattered evenly about the mean, and the majority of the data points are near the mean. Unfortunately, minor deviations from this model can cause major errors in the predicted estimates. Another model used to describe data is the nonparametric or robust approach. This approach allows deviations from our statistical model without causing large errors in the estimates. Both the parametric and nonparametric models have their place in examining hydrologic data. Remember, these models are only tools. We will first discuss the parametric tool.

Although statistics and statistical sampling have an important place in hydrologic studies, some important limitations apply to their use. Because of the stochastic behavior of many hydrologic events, probability distributions and data portrayal are useful. Remember that statistical inference only provides a framework for expressing probability differences. Statistical manipulation of data does not, indeed cannot, explain the reasons why something happens. Mathematical models fall into the same category; they are excellent tools to tell us what to expect, but they do not tell us why.

Too often when a data-collection study is in trouble because of a faulty design, the tendency is to salvage the effort with the use of statistics. In most instances, this type of operation only compounds the problem. The misuse of statistics can lead to the deadliest trap of all; the mathematical manipulation of unrelated, noncorrelated data into a probability function. 
When this occurs, everyone involved loses, but this situation occurs too frequently to ignore. If a statistical approach is used in the sampling scheme and data analysis, the hydrologist must play by the rules of the game at the beginning. Do not make all the moves of the game and then establish the rules. What about the rules of the game? Actually, they are simple even though they are frequently violated. They are as follows:

1. The variance of the sample must be independent of the mean of the sample. For example, a random distribution exists when the variance $\left(s^{2}\right)$ is equal to the mean $(\bar{x})$, that is, when $s^{2}=\bar{x}$. Now, the variance refers to the probability spread of the data, whereas the mean is the expected value. Both are statistics and both must be independent of one another. What this really says is that the samples must be collected without bias; one sample collected independently of the other and without any relation to the other. This is random or unbiased sampling.

2. The components of the variance must be additive. The variance of a sample includes all differences of sample error (both collection and analytical) and true differences (changes) resulting in time and distance. These differences must be additive, with each influence having an adjusted equal influence.

3. The data frequency must approximate a normal distribution to use a parametric model. If you are unfamiliar with the normal distribution you should consult any elementary statistical textbook. The normal distribution is a "bellshaped" curve, with a mean value dissecting the center of the "bell." On the left are values less than the mean; on the right are values greater than the mean. In many instances, continuous data such as our chloride concentration, will approximate the normal distribution. That is, the chloride concentration may range from zero to some positive number in a continuous fashion; such as 1.1, 1.2, 1.3, and so forth. Count or discrete data may not approximate the normal distribution. That is, the count may be $1,2,3$, or $2,5,9$. There is no continuity between values. This is a problem with biological data because whole organisms, not part of them, are counted. Thus, count data must often be transformed if they are to approximate the normal distribution or curve.

Statistical equations can be used to tell how many samples you need if some samples have been col- lected and a measure of the variance of these samples has been computed. If some preliminary samples are available and something of the sample variance is known, an analysis of the data can be used to guide the future sampling effort.

It is impossible here to provide a complete discussion of statistical sampling. Some familiarity with the subject or the opportunity of the study chief to work side-by-side with someone having an understanding of statistical inference is assumed. Useful references for those familiar with statistical sampling are Gilbert (1987), Koch and Link (1980), McCall (1982), and Steel and Torrie (1980). Only a brief explanation follows; the intent here is to introduce statistical sampling into study design.

\section{Simple Random Sampling}

Random sampling requires that the samples be collected without bias and be representative of the entire population. The basic concept is to estimate the mean and measurement uncertainties, which requires that every time period, sampling unit, or other discrete unit that you decide to sample has an equal chance of being chosen. If you plan on collecting 10 samples during a 1-year period, choose the 10 days or periods of sample collection in an unbiased manner. Each period within the days of the year must have an equal chance of being chosen. The same is true whenever a finite number of sampling sites are available for you to select a few for sampling.

The mean of a simple random sample from a population is simply the sum of the values of the sample divided by the number of samples collected as shown in equation 1.

$$
\bar{x}=\frac{\sum_{i=1}^{n} x_{i}}{n}
$$

where $\bar{x}$ is the mean,

$n$ is the total number of data values, and

$x_{i}$ is the ith individual data value.

In its simplest form, the variance of the sample is the squared deviation of the individual values from the mean, divided by the total number of samples $(n)$ minus one (eq. 2). 


$$
s^{2}=\frac{\sum_{i=1}^{n}\left(x_{i}-\bar{x}\right)^{2}}{n-1}=\frac{\sum_{i=1}^{n} x_{i}^{2}-\frac{\left(\sum_{i=1}^{n} x_{i}\right)^{2}}{n}}{n-1}
$$

where $s^{2}$ is the sample variance,- -an estimate of the entire population variance,

$\bar{x}$ is the sample mean,

$x_{i}$ is the individual data value, and

$n$ is the total number of data points.

Remember, the variance is calculated from your samples and is an estimated variance of the entire population. Iman and Conover (1983) present a way to use this estimate to calculate a population variance.

Use a table of random numbers to determine sampling times, stations, and so forth. Every statistical text has such a table. You simply need to know or decide the total possible number of sites, days or events you can or are willing to sample. Then, starting at a given column or row in the table of random numbers, select those within the possible total number of events (Gilbert, 1987).

Referring back to our discussion of stochastic events, you may wish to determine the confidence limits of the mean of a particular constituent concentration, such as chloride. The first value you need is $5_{\mathbf{x}}^{-}$, or the standard error of the mean. This is simply the square root of the sample variance $\left(s^{2}\right)$ divided by the number of observations $(n)$ (eq. 3 ).

$$
s_{\bar{x}}=\sqrt{\frac{s^{2}}{n}}
$$

where $s_{\bar{x}}$ is the standard error of the mean or

$$
\text { standard deviation, }
$$

$s^{2}$ is the sample variance, and

$n$ is the total number of data points.

With the standard error of the mean determined, you can calculate the confidence limit about the mean-that is how much you would expect the mean to vary at a given probability level. This calculation requires students $t$-value at the given probability level. Actually, you should use the value of $\underline{t}$ at $n-1$ degrees of freedom. That is, if you have 20 observations $(n=20)$, then use $t$ at 19 . One note of caution, Hirsch and others (1982) indicate that the $\underline{t}$ statistic may be misleading for hypothesis testing if seasonal cycles are present in the data (see "Data Examination" section). The confidence or fiducial limit of the sample mean is calculated by using equation 4 :

$$
\bar{x}=(t)\left(s_{\bar{x}}\right)
$$

where $\bar{x}$ is the sample mean,

$\underline{t}$ is the student $\underline{t}$ variate, and

$s_{\bar{x}}$ is the standard deviation.

From a randomly collected preliminary sample, it is possible to determine the number $(n)$ of samples needed to determine the mean $(\bar{x})$ within some preselected percentage error of the mean (eq. 5):

$$
n=\frac{t^{2 s^{2}}}{L^{2}}
$$

where $n$ is the number of samples,

$t^{2}$ is the square of the student $t$ variate,

$s^{2}$ is the variance, and

$L^{2}$ is the confidence interval-your selected data-quality objective.

The allowable error can be considered as your data-quality objective. In using equation $5, L^{2}$ and $s^{2}$ need to be in the same units. The value of $t$ is approximated in this case as 2 ( $t$ at 95-percent level for a twosided test when $n=$ infinity, (Gilbert, 1987, p. 138), and $s^{2}$ is the variance of a simple random sample as calculated in equation 2. Do not try to be too precise here, for the results may be unobtainable. Note that $L$ in equation 5 is squared. Thus, a 5 -percent allowable error would require four times as many samples as a 10 -percent allowable error.

Simple random sampling has a place in hydrologic investigations, but is limited because the variance is often too great, or the hydrologic system under investigation is too variable with regard to its component parts. Fortunately, the component parts of most hydrologic systems vary within a definite and repeated pattern, and their variability can be reduced and better understood using stratified-random-sampling techniques.

\section{Stratified Random Sampling}

Stratified random sampling is useful when the strata (stratum if singular) are distinct - that is, have known sizes and boundaries. Another requirement for using stratified random sampling is that the individual stratum should be more homogeneous than the combined strata. In most hydrologic systems, this is the case. 
Many inexperienced study chiefs have difficulty in defining a stratum. They think of it in terms of a physical boundary such as a stream-bottom type, or a pool or riffle. Now, stream-bottom types and pools and riffles are types of strata. But a hydrograph or a streamtemperature record also can be divided into distinct strata. We will discuss this more in the following paragraphs and provide some examples. Let us first discuss some equations related to stratified random sampling.

The overall mean of a stratified random sample is calculated by simply summing all the observations from all the strata and dividing by the total number of observations (eq. 6):

$$
\bar{x}=\frac{\sum_{i=1}^{k} n_{i} \bar{x}_{i}}{\sum_{i=1}^{k} n_{i}}=\frac{n_{1} \bar{x}_{1}+n_{2} \bar{x}_{2}+\ldots+n_{k} \bar{x}_{k}}{n}
$$

where $\bar{x}$ is the estimated sample weighted mean,

$n$ is the number of samples,

$n_{i} \bar{x}_{i}$ is the arithmetic mean of $n_{i}$ observations, and

$k \quad$ is the number of intervals.

The variance of a stratified random sample (eq. 7) is more complicated, but is not difficult to calculate (Gilbert, 1987).

$$
s \frac{2}{x}=\sum_{i=1}^{k}\left(\frac{N_{i}}{N}\right)^{2}\left(\frac{s_{i}^{2}}{n_{i}}\right)\left(1-\frac{n_{i}}{N_{i}}\right)
$$

where $s_{x}^{-2}$ is the variance of the sample mean,

$N_{i}$ is the number of sampling sites in the ith stratum,

$N$ is the number of units in all strata,

$s_{i}^{2}$ is the variance of samples taken in the ith stratum, and

$n_{i}$ is the number of samples taken in the ith stratum.

If the sampling sites or units exceed 10 percent of the total sampling sites in the stratum-that is, if $\frac{n_{i}}{N_{i}}$ exceeds 0.1 -then a finite correction factor calculated as $1-\left(\frac{n_{i}}{N_{i}}\right)$ is needed. The standard error of the mean $(s \bar{x})$ of a stratified random sample is simply the square root of the variance (eq. 8).

$$
s_{\bar{x}}=\sqrt{\sum_{i=1}^{k}\left(\frac{N_{i}}{N}\right)^{2}\left(\frac{s_{i}^{2}}{n_{i}}\right)\left(1-\frac{n_{i}}{N_{i}}\right)}
$$

where all terms are the same as in equation 7.

That is enough discussion about statistical equations. Our interest here is in defining each stratum within a group of strata and how stratified random sampling is used to design the sample-collection frequency. As mentioned earlier, pools and riffles in a stream are obvious strata. Less obvious strata are those found on a discharge hydrograph. For the sake of simplicity, an example is a hydrograph divided into four strata (fig. 17).

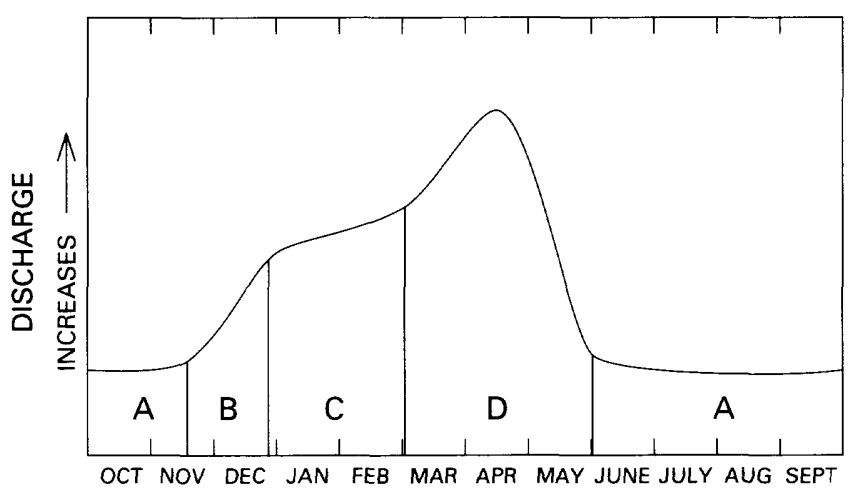

Figure 17. An example of a hydrograph having four strata.

One could argue that strata $C$ and D really should be further divided, but be careful not to be too strict in defining your strata. We just want to get some idea of how many samples we need to collect in each stratum. Essentially, two approaches can be used for stratified random sampling techniques. One approach is proportional allocation; the other approach is optimum allocation.

With proportional allocation, no data from preliminary samples are needed. What is needed, however, is some idea of the total number of samples you are willing or can afford to collect, and some measure of the boundaries of each stratum-that is, the fraction of each to the whole. In this hydrograph example (fig. 17), time could be used-the number of months (or days) included in stratum A, B, and other strata. We divided our hydrograph into four strata on the basis of months of similar discharge. Assume we can collect a total of 50 samples of a flow-related constituent. How many samples should be collected at a particular discharge (stratum) using proportional allocation? 
The equation for proportional allocation is

$$
n_{i}=\left(\frac{N_{i}}{N}\right)(n)
$$

where $n_{i}$ is the number of samples in the ith stratum,

$N_{i}$ is the total number of sampling units per

stratum (in this example, months),

$N$ is the total number of sampling units in all strata (in this example, months), and

$n$ is the total number of samples to be collected. (in this example, $\mathrm{n}$ is 50 ).

Therefore, our example has 6 months in stratum A, 1 month in stratum B, 2 months in stratum C, and 3 months in stratum $\mathrm{D}$. The proportional allocations determined from our example hydrograph (fig. 17) are given in table 2 .

Table 2. The proportional allocations determined from the example in figure 17 for the number of samples per stratum

I $\frac{N i}{N}$, months per stratum $\left(N_{i}\right)$ divided by $12(N) ; n$, total number of samples to be collected; $n_{i}$, number of samples per stratum]

\begin{tabular}{cccc}
\hline $\begin{array}{c}\text { Stratum } \\
\text { (fig. 17) }\end{array}$ & $\boldsymbol{N}_{\boldsymbol{i}}$ & $\boldsymbol{n}$ & $\boldsymbol{n}_{\boldsymbol{i}}$ \\
\hline $\mathrm{A}$ & $(6 / 12)$ & $(50)$ & 25 \\
$\mathrm{~B}$ & $(1 / 12)$ & $(50)$ & 4 \\
$\mathrm{C}$ & $(2 / 12)$ & $(50)$ & 8 \\
$\mathrm{D}$ & $(3 / 12)$ & $(50)$ & 13 \\
\hline
\end{tabular}

One obvious problem with the proportionalallocation technique from the standpoint of determining variability in sample concentration is that one-half of the samples will be collected during low flow when the discharge and constituent concentration might vary little. However, a measure of concentration variability is important, which means that most of our samples should be collected when conditions are rapidly changing and the variability among constituent concentrations is greatest. Preliminary samples or a reconnaissance study is the way around this pitfall. Then, employ the optimum-allocation approach based upon the variability of constituent concentration in each stratum. An optimum-allocation approach requires that, in the absence of existing data, a preliminary reconnaissance study is established to determine concentration variability. A cautionary statement is needed here: $\mathrm{DO}$ NOT let the preliminary reconnaissance effort become the entire study. Design the reconnaissance study to collect data for the sake of determining concentration variability for optimum- sample allocation and nothing else.

Using the preliminary measurements from each stratum, compute the sample variance $\left(s^{2}\right)$ for the stratum exactly as the variance of a simple random sample (equation 2). The square root of the variance is the standard deviation $\left(s_{i}\right)$. Now establish a table (table 3 ) to determine sample size for each stratum.

Table 3. Example optimum-allocation table used to determine the sampling frequency for each stratum in the example hydrograph in figure $17\left(\sum N_{i} s_{i}\right.$ is 79.3$)$

$\left[N_{i}\right.$, number of months in a stratum; $s_{i}$, standard deviation of each stratum; $\frac{\mu S}{\mathrm{~cm}}$, microsiemens per centimeter at 25 degrees Celsius]

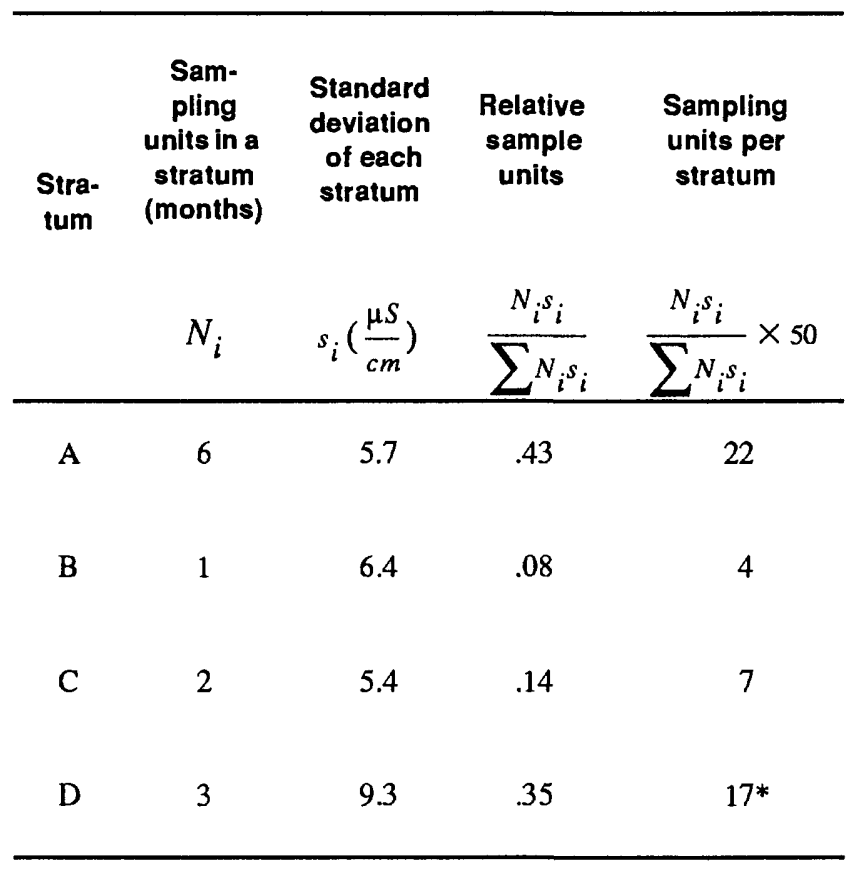

\footnotetext{
*Asterisk indicates the number was rounded so that the total number of samples equals 50 .
}

In our example (fig. 17), suppose the following standard deviations of specific conductance for the four strata $\mathrm{A}$ - D are:

5.7, 6.4, 5.4, and 9.3 microsiemens per centimeter at 25 degrees Celsius.

Assume that a total of 50 samples will be collected. Using these assumptions, an optimumallocation is calculated (table 3 ). 
The proportion-(table 2) and optimum-(table 3) allocation schemes present different numbers of samples for strata A, C, and D. The adjustment of the number of samples to collect in each stratum using the optimum-allocation approach is based upon the sample variance that was determined from preliminary samples.

Obviously, most hydrographs are more complex than that given in figure 17, but most hydrographs can be divided, for practical purposes, into six strata or less. Do not be too exact in defining the strata, but separate the strata of rapid change from those of little change.

The USGS publishes daily specific-conductance data as a function of discharge in annual data reports. This information can be used to determine the expected variability in the major chemical constituents such as calcium, sodium, sulfate, chloride, and so forth. If these examples seem too simplified or "unreal," look at the USGS annual data reports and use the published specific-conductance data as real examples. If there are too many specific-conductance data, simply define the strata (on the basis of time and discharge) and select a predetermined number of values within each stratum using a table of random numbers. It's as simple as that.

Stratified random sampling can be effectively used in the selection of wells completed in a particular aquifer. The strata could be deep or shallow wells, or all wells deeper or shallower than a given depth. Obviously, well logs are needed to ensure that a given well is placed in the correct stratum.

A well field having wells of different depths (and hence several strata) provides an example for comparing simple random sampling to stratified random sampling. Assume that the measurement under consideration is dissolved-solids concentration, and, as is typically the case, the water in the shallow wells will have a lower dissolved-solids concentration than water in the deeper wells. If you randomly sample without regard to depth, some selected wells will have a low and some wells will have a high dissolved-solids concentration. The range in dissolved-solids concentration among wells will be high, as will the sample variance. From these data, a mean dissolved-solids concentration, and hence a standard error of the mean and associated confidence limit, can be determined. A note of caution: the dissolved-solids mean may be biascd if seasonal concentration trends or pollution affects the concentration. Although useful, the high variance of these data will be somewhat difficult to analyze, and some useful information such as comparative and individual dissolved-solids concentrations for deep and shallow wells, as well as associated chemical data, may be masked.
In contrast, if stratified random sampling is used, the information is more specific and is not masked by variable well depths. Moreover, the variance among samples is decreased because the dissolved-solids concentration in each stratum is more homogeneous than the dissolved-solids concentration in the combined strata. Stratified random sampling also provides two excellent approaches for determining the number of examples to be collected in each stratum-proportional or optimum allocation.

As mentioned earlier, one of the primary problems in the use of stratified random sampling is in defining the strata. In the examples given, discharge, time, and well depth were used. Stream bottom material such as rubble, sand, and so forth were given as examples.

As a guide to recognizing possible strata in hydrologic systems, some examples are given in table 4 . This list is by no means complete, and you should be able to add other examples within your own discipline.

Table 4. Examples of hydrologic systems and associated strata types

\begin{tabular}{ll}
\hline Hydrologic system & \multicolumn{1}{c}{ Strata types } \\
\hline Stream or river & Discharge per unit time \\
& Slope \\
& Pools and riffles \\
& Geomorphological characteristics \\
& Shoreline vegetation types \\
& Bottom material types \\
& Losing or gaining reaches \\
& Areas above and below impoundments \\
& Drainage areas \\
& Diel (daily) changes in dissolved gasses \\
& \\
Lake and reservoirs & Thermal zones \\
& Chemical zones \\
& Littoral, limnetic, profoundal zones \\
& Shoreline vegetation areas \\
& Depth of biological material \\
& \\
& Tidal changes \\
& Salinity zones \\
\hline
\end{tabular}

It is always good practice to think in terms of strata when designing a study, even if proportional or optimum allocation are not used to assist in determining the number of samples to collect. After all, thinking in terms of strata is really a beginning in thinking 
about possible variability, periods of abundance and nonabundance of constituents, and constituent concentrations, like you did in "The Framework of the Study" section.

\section{Cluster (Two-Stage Sampling)}

Another stochastic sampling model is two-stage sampling, which is a hybrid type of stratified random sampling. Two-stage sampling involves cost ratios between sampling primary $\left(c_{1}, n_{1}\right)$ and secondary $\left(c_{2}, n_{2}\right)$ sampling units. The system being studied is divided into strata - the primary units. Within each strata, some samples are collected; the strata are subsample, providing the secondary units.

Two-stage sampling is frequently used by opinion takers. As an example, the primary units may be the number of cities to include in the poll, and the secondary units are the number of people to interview within each city. The objective is to determine how many samples are needed to reduce the sample variance without exceeding a given cost. It may be found, for example, that a reduction in sampling strata (cities, for example) with the subsequent collection of more subsamples (people interviews) will provide a lower variance, at less cost, than the establishment of more strata (cities) and the collection of fewer samples (people interviews) in each stratum.

To use the cluster sampling method, you need an estimate of the cost, $c_{1}$ and $c_{2}$, for the primary and secondary units, and a within and between variance of the parameter concentration for the several strata being sampled. The total cost $(C)$ of sampling the primary and secondary units is:

$$
C=c_{1} n_{1}+c_{2} n_{1} n_{2}
$$

where $c_{1}$ and $c_{2}$ are the costs of sampling $n_{1}$ and $n_{2}$, the number of primary and secondary units, respectively. With the variance and cost factors computed, the number of samples to collect in the secondary units (that is, the number of samples to collect in each stratum) can be estimated by the equation:

$$
n_{2}=\sqrt{\frac{c_{1} / c_{2}}{s_{1}^{2} / s_{2}^{2}}}
$$

where $c_{1}$ and $c_{2}$ are cost factors for the primary and secondary units, and $s_{1}^{2}$ and $s_{2}^{2}$ are between- and within-sample variances respectively.

Now, there is a bit more to the use of this technique than given here. We refer you to some easy-to- follow references such as Snedecor and Cochran (1967, p. 528-534), Poole (1974, p. 300-303), and Cochran (1977, p. 276-279). The point is that cluster or twostage sampling can be quite useful in the design of some types of hydrologic studies because the true mean for each subunit can be calculated (Gilbert, 1987), and because this technique involves a cost factor in its calculation-a factor of great importance in study design.

\section{Systematic Sampling}

Another sampling technique used for hydrologic studies is systematic sampling, which consists of randomly selecting the first sampling site or time of sampling, and then selecting the remaining sampling sites at some predetermined space or time interval. This simple technique can easily be used in most hydrologic studies, but has serious limitations in that the samples may be biased. Most importantly, there is no reliable method to estimate the standard error of the sample mean using the systematic method. Systematic sampling is based on the random distribution of the constituents of interest, but random distributions rarely are found in natural or contaminated areas. However, Gilbert (1987) suggested that for reconnaissance studies, when determining the presence or absence of constituents is the objective, systematic sampling is a useful approach.

\section{Data Examination}

At the beginning of this section of the report, statistical models were mentioned. The normal distribution model, represented by the mean and variance, is the model commonly used for earth-science data. The parametric- or classical-statistical tests are, in many cases, more powerful than the corresponding nonparametric tests if the data meet the parametric requirements (Dixon and Massey, 1983). However, Huber (1981) pointed out that seemingly small deviations from a normal (parametric) distribution can cause a totally unacceptable and misleading conclusion about the true tendencies of the constituent being studied. That is, the mean and variance may be too large.

A nonparametric (robust) statistical approach to determining the midpoint of your data, known as the median, is found by calculating the 50th percentile. The sample median is, therefore, another estimate of the data midpoint and, thus, estimates the midpoint of the entire population-similar to the mean. The median is reasonably unaffected by the extreme values (outliers), whereas the mean usually is affected significantly by outliers. The fact that the median is resistant to the magnitude of the outliers, reduces the need to 
remove the outliers from the tails of the distribution when determining the mean. Rejection of outliers may cause the distribution of the data to become nonnormal.

A good question at this point would be, why use statistical methods that require a normal distribution? One answer is that if the data are normally distributed, statistical tools like the $\underline{t}$ and $\mathrm{F}$ tests are not only powerful, but also well understood by the users of scientific data. A second answer is that a mean and its variance take into account the total of all the data (Shapiro, 1986), which makes the mean a good estimate of the central tendency of uniform data correlated over space and time. Some nonnormally distributed data can be transformed by simple mathematical operations to become normally distributed, therefore allowing parametrical statistical tests to be used. Shapiro (1986) and Elliott (1977) presented several tests for normality because regression, correlation, and similar tests are so ingrained in the literature; and these tests require normally distributed data.

The study chief who has not decided on the statistical model to be used can examine the data using exploratory-data analysis. Boxplots, box-and-whisker plots (Velleman and Hoaglin, 1981), and stem-and-leaf diagrams (Chambers and others, 1983) visually display the data and show the distribution of the tails, which makes the outliers apparent. If analysis indicates that the distribution of the tails are uneven or that the outliers are in one tail and not the other, it is time for a decision. The study chief must either decide to test the data to determine if the distribution is normal, or simply use nonparametric or distribution-free techniques initially (Dixon and Massey, 1983).

The decision to use a nonparametric sign test (Iman and Conover, 1983) instead of the parametric $t$ test can be difficult. For example, the sign test, the signed-rank test or Wilcoxon signed-rank test, and the Wilcoxon-Mann-Whitney rank-sum test are all nonparametric tests designed to replace the $t$ test. Helsel and Hirsch (1992) attempted to reduce this confusion by listing parametric tests and the corresponding nonparametric tests. Table 5 is an expanded listing of statistical test comparisons. Again, you need to remember that statistical tests are just another tool to assist your understanding of the data. For example, if your goal is to test a hypothesis and you do not like the result, determine the reasons that the hypothesis tested appears to be wrong rather than trying another test that might give you the result you wish.

The study chief needs to resist trying several different statistical tests to get an answer and must not ignore outliers. Outliers are as important as any other result and may be the product of some collection and measurement error, such as sample contamination, poor sampling technique, instrument malfunction, and similar problems. Each predictable source of error needs to be considered each time an outlier is identified; however, the outlier may actually represent a portion of the data distribution in the stratum. It is nice to think that each of the chosen stratum are homogeneous, but they are not; samples from heterogeneous strata probably will produce data that appear to be outliers. Also, some data can vary with season, discharge, pollution, or some combination of variables that may look like outliers to a statistical test. Try first to determine if the outlier is an artifact of something you did; if the result does not appear to be caused by the collection and measurement process, investigate possible hydrologic causes.

If you are making a biological study, it would be useful for you to review the 10 principles by Green (1979) relating to study design and statistical analysis of your data. Green (1979) also presents study sequences on optimal and suboptimal environmentalimpact study design. Also, you should consider the four criteria for choosing a sampling plan presented by Gilbert (1987).

\section{The Work Scheduie}

As mentioned in the section "Relating Hydrologic Properties," a data-collection-requirement matrix needs to be designed to schedule our data collection. A suggested format is shown in table 6 .

Table 6 is simple to prepare, and it is easy to cover the entire life of a 2-year study. However, if the study is to be over several years duration, choosing sampling dates more than a year in advance may not be beneficial. The goal at the moment is to ensure that the frequency of sample collection is adequate. Note that the sampling stations are not filled in. This was not from neglect, but because the study has not yet reached that point in the study design. The goal at the moment is to ensure that the frequency of sample collection is adequate. Sampling stations can be added to the matrix later, after everyone is satisfied that their selection will help solve the defined problem. The sampling station locations can be listed under explanatory notes at the bottom of the matrix.

The data-requirement matrix for the study will become a part of the planning report described in the section “The Wrap Up." A computer spreadsheet can be used as your matrix. When the matrix is completed and the study is underway, the matrix can be used for easy reference for what and when to sample or measure. If someone on the study besides yourself does the data collection, they can use the data-requirement 
Table 5. Appropriate parametric and nonparametric hypothesis tests (modified from Helsel and Hirsch 1992, p. 105)

\begin{tabular}{|c|c|c|}
\hline \multicolumn{2}{|c|}{ Hypothesis tests } & \multirow{2}{*}{ Reference } \\
\hline Parametric & Nonparametric & \\
\hline \multicolumn{3}{|l|}{ t-test } \\
\hline \multirow[t]{4}{*}{ Two-sample } & Sign & \\
\hline & Wilcoxon-Mann-Whitney & Iman and Conover, 1983 \\
\hline & Two-sample run & Dixon and Massey, 1983 \\
\hline & Mann-Whitney & Helsel and Hirsch, 1992 \\
\hline Paired & Wilcoxon & Helsel and Hirsch, 1992 \\
\hline \multicolumn{3}{|c|}{ Analysis of variance } \\
\hline Independent & Kruskal-Wallis & Conover, 1980 \\
\hline (1-way) & ANOVA on ranks & Helsel and Hirsch, 1992 \\
\hline Related & Friedman & Conover, 1980 \\
\hline (2-way) & 2-way ANOVA on ranks & Helsel and Hirsch, 1992 \\
\hline \multirow[t]{2}{*}{ Linear regression } & Mann-Kendall & Gilbert, 1987 \\
\hline & Monotonic & Helsel and Hirsch, 1992 \\
\hline \multirow[t]{2}{*}{ Correlation } & Kendall's tau $(\tau)$ & Conover, 1980 \\
\hline & Spearman's rho $(\rho)$ & Helsel and Hirsch, 1992 \\
\hline Mean & Median & Iman and Conover, 1983 \\
\hline Variance & $\begin{array}{l}\text { Interquartile range } \\
\text { (F-pseudovariance) }\end{array}$ & Hoaglin and others, 1983 \\
\hline
\end{tabular}

matrix as a guide. A final attribute of the matrix is that it informs your supervisor where the study staff will be on a particular date and what you will be doing.

\section{WHERE TO SAMPLE}

A sample is a part representing the whole; and we ask, or at least assume, a great deal from a sample or a measurement. It is therefore important that we carefully select where we collect our samples and make our measurements. We realize that a single sample may not represent the whole or even define the average condition of the system. We collect, therefore, many samples at a variety of places because we hope that we can define the average and the extremes, as well as other attributes of the system. Too frequently, we collect many more samples or make many more measurements at more sites than necessary. Oversampling seems to provide a cloak of security to some study chiefs. However, oversampling is expensive and, as discussed several times earlier, is a rather slipshod way of conducting a study; more importantly, oversampling reduces thinking, a necessary activity for study success.

There are no fail-safe techniques to use in selecting sampling sites or stations. Each organization prepares numerous guidelines, manuals, and complete treatises to assist the investigator so that a good sample can be obtained. These manuals will not cover all eventualities, but can help the investigator improve the probability of selecting a suitable sampling site.

Recall that in the section "Determining What to Measure," we decided that each constituent should pay its way. The same philosophy is valid with the selection of sampling sites or stations. Therefore, each sampling station also should pay its way. If a station does 


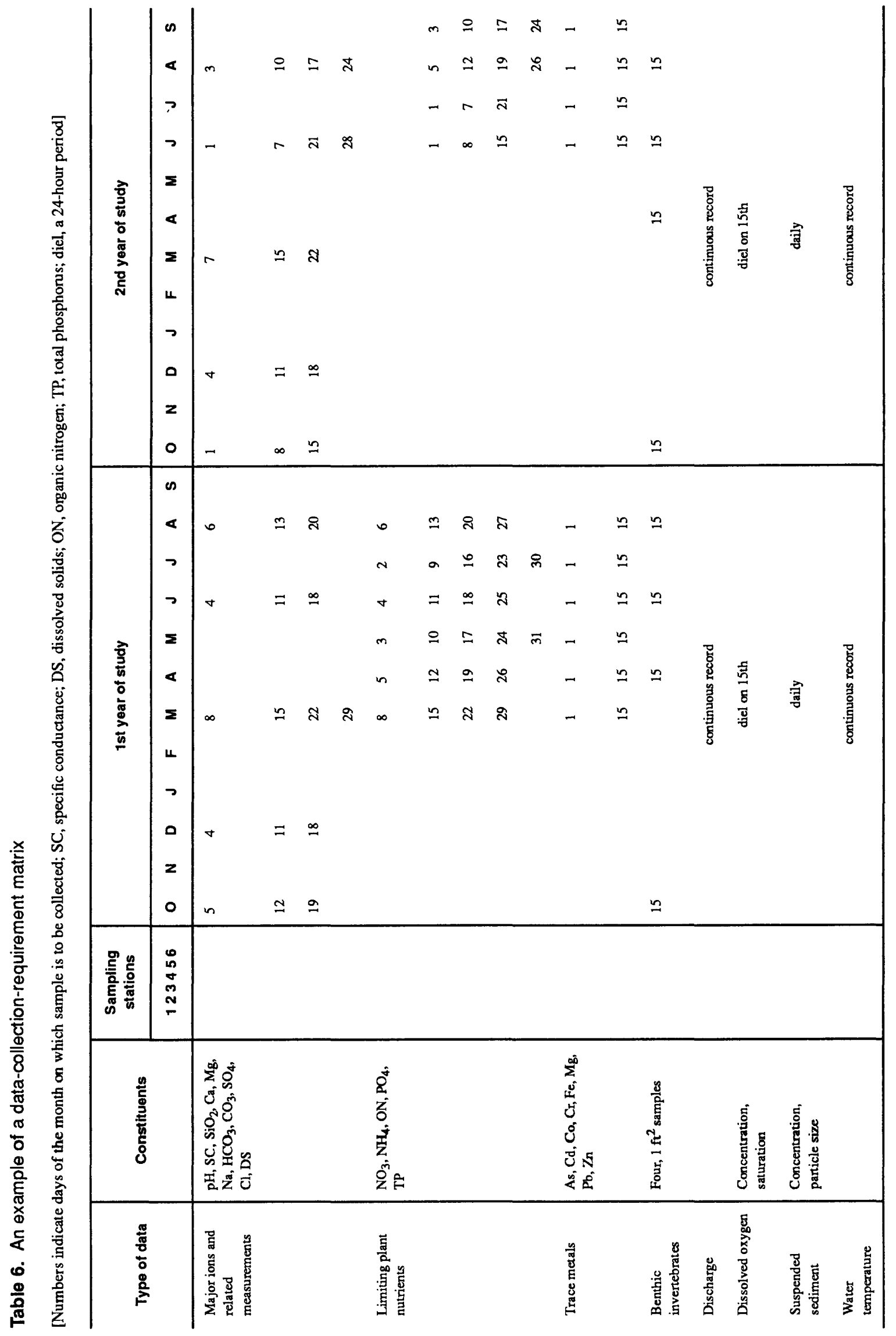


not, then you will spend a great deal of time and money traveling to unnecessary places and collecting unnecessary data. Depending upon the complexity of the study, each station will require time for study staff to sample and make measurements, cost money for sample analysis, and require time and money for the study chief to analyze the data. Remember, too, that constituent selection, frequency of collection, and station or site selection are like the legs on a three-legged stool. One is as important as the other. And, each deserves the same amount of hard thought in selection. Shortcutting one affects all the others.

Begin the site selection by preparing the dataquality objectives, which need to clearly define the hypotheses to be tested during the study. If constituents are sorbed to sediment and the goal of the study is to define their distribution in the system, then sites must be sampled where uplift of bed material by stream velocity is minimal. Scour limits the use of bridge piers as sites for the collection of a representative sample. On large rivers, collection at bridge sites where the piers influence the flow is the only available place. If you must sample at such sites, always clarify in the study design that sampling at a bridge was necessary, and describe in detail any factors that might result in the sample not being representative of the system. You must describe all factors and influences that make the sample nonrepresentative. Write these factors and influences down before selection of the sampling site, and if in your judgment they make the data questionable, reject the site. Remember that questionable data will lead to questionable interpretations.

The sampling sites chosen should be selected so that a representative sample can be collected at both high and low flows. High- and low-flow sampling refers not only to being able to make a measurement upon reaching a site, but also to being able to access the site during winter weather or storm conditions. Frequently, this will not be a problem, but sometimes you must use a helicopter or other nonconventional methods to collect the samples. When such equipment is needed, justification of the sampling site becomes more critical; you must include the cost in the study budget.

In many water-quality reconnaissance studies, the primary plan is to collect water samples and make field measurements near effluents. An upstream sample acts as a control, and the downstream sample is used to illustrate the change in water quality that results from the mixing of the effluent with the receiving stream. Although seemingly simple, this scheme has served the USGS quite well. If a part of the study objective is to determine effluent effect on receiving water, then the upstream and downstream technique has some merit in the study. Use some caution, how- ever, and be certain that the upstream station is a good control. That is, be certain the upstream station is not affected by effluents above it. Mixing also may be incomplete at both the upstream and downstream stations. Frequently, mixing or the lack of mixing can be determined by making simple specific conductance or suspended-sediment measurements. Regardless of what technique you use, always determine the mixing patterns of effluents upstream and downstream.

Remember to collect the facts on the physical surroundings, and try to assess how this information will influence the sample.

Tributaries must always be considered in the selection of a sampling site or station. A tributary may or may not have an influence on the quality (or other characteristics) of the receiving stream. These influences are only determined by sampling or making measurements above, below, and in the tributary streams. The problem with this plan is that frequently including all of the tributary streams in the sampling-site selection in the study is not possible. Consequently, you must predetermine the criteria by which to accept or reject tributaries as a part of the sampling program. The safest way to do this is to use a preliminaryreconnaissance sampling plan. Fortunately, you can conduct this preliminary study at low-flow periods because many biological and chemical constituents have their highest densities or concentrations at that time. Because time is frequently critical, you may have to anticipate the influence of tributaries on constituent concentrations such as fluvial sediment at high or intermediate flows. Use care when planning the reconnaissance sampling, or misinformation will hinder the study.

Regardless of the techniques used, the influence of each tributary must be considered. Because you cannot sample each tributary, prepare a written list of criteria for selecting or rejecting a particular tributary as a sampling site. Some suggestions follow:

1. Know well the physical characteristics of the system that will be studied. Consider such things as drainage area, lithology, and use of the basin. A large drainage area, a varied lithology - or at least one different from the main stem, and extensive anthropogenic use of the area are factors that indicate the tributary should be included in the sampling program.

2. Consider the dissolved-solids concentration or the specific conductance of the tributary. If during low-flow periods, the specific conductance or dissolved-solids concentrations are higher or lower when compared to the main-stem flow, 
this is a strong reason to consider the tributary as a sampling and measuring site.

3. Look for sediment plumes and sand and gravel bars near the mouth of tributaries. The presence of these features are indicators of upstream erosion. Tributaries having sand bars near their mouth should at least be considered as part of the sampling-site program.

4. Consider establishing a sampling and measurement site at the mouth of a tributary that provides a significant discharge to a main stem. Discharge is a relative hydrologic feature, that is, relative to the main stem where the tributary joins. An upstream tributary's discharge may be small compared to the downstream main stem, but the tributary may contribute significant suspended sediment and trace metals to the main stem. Do not select tributaries for sampling on the basis of discharge alone. Base the selection on discharge in relation to where the tributary joins the main stem.

5. Consider establishing some sampling stations on a tributary other than at its mouth if the tributary is of sufficient discharge and differing water quality to influence the main stem.

These are but five sample criteria that come to mind in selecting or rejecting tributaries as a part of the sampling-site program. Constituents that are easy to measure on-site, yet provide insight to water-quality conditions between a tributary and the main stem are water temperature, specific conductance, $\mathrm{pH}$, and dissolved oxygen.

At a minimum, you should determine if the tributary has a different water quality than the main stem, but do not let this activity overtake the designed study. Such determinations are the "tail of the dog." Return to the primary study objectives as soon as possible, or make tributary sampling a significant part of the study and adjust the study objectives accordingly.

In selecting wells for sampling, information about the aquifers in question, their areal extent, individual well logs, and wellhead design are important and in most cases necessary (see "Stratified Random Sampling" in "How Much-The Frequency of Sampling" section). Choosing the wells to sample in the absence of other information frequently wastes resources even if the selection is based upon a review of well logs. Shallow wells need to be described as well as deep wells, and wells in aquifer A need to be defined, as well as those in aquifer B. Sampling problems can include inactively pumped well, insufficient access to well, or no sampling opportunities at the wellhead.
The selecting and sampling of wells as you come across them is not recommended. First, the sample frequently will be biased, or if the sample isn't biased, how will you prove otherwise? Second, wells may be sampled for which logs do not exist. Third, such sampling is expensive and you can waste a great deal of money and time collecting useless data. No one will ever doubt your ability to gather numbers. What will always be questioned is your ability to gather useful numbers-numbers that help explain hydrologic events.

If you are unfamiliar with wells in an area, make a reconnaissance of their location and use this opportunity for some preliminary sampling. Obtain from the proper authority the needed well logs, depths, ownership, and so forth. Then, and only then, select the wells for sampling. Think about the access, season of maximum use, type of use, depth-to-water, and area geology. Sampling during the reconnaissance may seem easy, but each ground-water sample must be collected to ensure the reliability of the constituent concentration. You are actually interpreting the reconnaissance data when the wells are selected for future sampling.

Lakes and reservoirs can be complex systems insofar as selecting sampling sites is concerned. In the formation of reservoirs, stream valleys are drowned and each area may become a miniature reservoir with its own hydrologic patterns. These stream valleys or "arms" must be taken into consideration in the selection of sampling sites. The investigator must consider depth of the valleys, as well as mixing by the wind. Consider if the valleys are too deep for complete mixing by the wind, if the valleys are protected from prevailing winds, and if the water depth is sufficient for thermal stratification in the summer.

The main axis of a reservoir may be extremely long, with a gradual slope from the dam upstream to the inflowing river. Sampling such a system could require a large number of sites, with the cost of sampling each site quite high. Consider a large reservoir much like a slow-flowing river. This does not imply that the flow in a reservoir is always unidirectional, but the mass flow is towards the outlet. If your resources are limited, you may have to view the system in this manner, but be certain that you delineate this framework or hypothesis in the report.

An instrument that can make several field determinations is useful for reconnaissance studies. These units record rapidly and provide information about water temperature, specific conductance, dissolved oxygen, and $\mathrm{pH}$. With this instrument, you can make rapid measurements to determine constituent variations among areas such as the main stem and drowned tributary channels. Probably the best time to make such a 
preliminary reconnaissance is in midsummer, after the reservoir has been thermally stratified for a period of time.

Consider the biological and thermal zones in a lake. The littoral zone is shallow, and light penetrates to the bottom. This is the zone of highest biological production, and thus the uptake and release of elements by plants and animals is greatest. The epilimnion and metalimnion are the zones of phytoplankton production in lakes and reservoirs; the chemical quality there also may be greatly influenced by biological activity. As the wind circulates the water in the epilimnion, diel temperature changes frequently occur, and these temporary changes may result in the uptake or release of materials by organisms.

Water in the hypolimnion is not in contact with the atmosphere. Thus, if bacterial respiration is excessive, this deep-water zone can soon be exhausted of dissolved oxygen, and anaerobic conditions will develop. When the hypolimnion becomes anaerobic, a number of things happen, including the dissolution of iron, manganese, and phosphorus and a host of other trace elements. In addition, the decomposition rate of sinking organic matter is reduced under anaerobic conditions.

The point to remember is that the thermal zones (strata) in a lake or reservoir can be quite different from one another, and you may need to describe these differences and their magnitudes to successfully complete the study. Any selected surface site necessitates consideration of the zones below it if the system is to be described.

Do not forget areas of sediment deposition into lakes and reservoirs. These are frequently areas of potential enrichment and may have a profound influence on the lake or reservoir in the future. Consider some grab or dredge hauls in the sampling program to delineate these areas. You also may wish to further delineate the sites with a bathymetric map of the lake or reservoir if such is not already available.

Make every effort to carefully locate the sampling sites or stations each time you visit them. The best way is to establish a permanent buoy at the site. If this is not possible, some type of locating method using a direction finder is useful.

Give the site-selection phase of the study design careful thought. Select or reject sites on a logical basis and write down the reasons for accepting or rejecting a site. File these reasons so that you can refer to them later if you have doubts or second thoughts. There is no single quantitative method for sampling-site or station selection. You simply must select the sites to suit your needs.

\section{Quality Assurance}

Although quality assurance is currently (1993) a popular phrase, it has existed for decades and is really just good scientific practice, which has an important role in study planning, implementation, and report writing. You need to decide during the study-planning process if a study quality assurance plan is needed for the investigation or study. Gilbert (1987) stated during his overview of sampling design that an investigator should prepare a quality assurance plan that covers all aspects of the study and not be limited to just sample collection and laboratory analysis.

One reason to develop a quality assurance plan as a part of your study, is that the plan will help clarify the expectations of you and your supervisor. In the previous section, we suggested that you write down the reasoning used to make your decisions. This is really a principle of quality assurance. Some other comments related to quality assurance are:

1. Some, but not all studies need a formal, written quality assurance plan. You must determine if your study warrants this effort.

2. Frequently, the quality assurance activities may be incorporated into the study work plan. The quality assurance activities describe the effort needed to provide you the security that the work plan is implemented adequately and that the data meet the objectives stated in the study purpose and scope. Also, the quality assurance activities may assist the study staff to reach your expectations.

3. If others are doing the sampling, ensure that they understand the sampling design and procedures. Two people may not perform a written procedure in the same manner. Use your reconnaissance or pilot study to impart the need for uniformity in the data-collection procedures. Be sure you tell other people associated with the investigation what is expected of them.

4. Before each phase of the study begins, read the work plan you prepared and think about the study objectives. Think about the quality assurance requirements as an attempt to decrease the chances for needless work.

These comments are probably self-evident to anyone who designs studies. Remember that others around you probably also have designed a study. Ask them what pitfalls were encountered during and after the design of their study. You cannot eliminate all the 
errors during the study implementation, but you can reduce the errors by using a little care and thought.

\section{THE WRAP UP OF A SURFACE-WATER QUALITY STUDY}

The end is near. In the next section, you will write a contract between yourself and all who would question or enter your domain, but before you do so, let's make certain that everything is in order. Check to be sure that the problem is thought out in detail, and that the conceptual framework is in place now that you are studying how the hydrologic system works. Be especially certain that you have clearly defined the problem. If you are not satisfied with the problem definition, start again and adjust the study accordingly. At the risk of repetition, you must clearly define the problem, or all your effort is wasted. Next, be certain your constituent collection and measurement list is satisfactory and clearly defendable. Can you defend the frequency of collection? Are the collection and measurement sites located at places where they will provide the information the investigator needs to solve the problem as defined? This is the check list presented in table 6. This is not time to come up short on anything.

\section{The Bite of the Line}

In western forests, logs are frequently removed with a tractor. The logs are connected to the tractor with a cable (line) containing a noose or "choker" on the end. Once the "choker setter" places the noose around the end of the $\log$, he rapidly moves to one side so that if the cable should slip or break, he will not be in the "bite of the line." However, if the line is in excellent condition and the choker set securely on the log, there is little danger of slippage or breakage. A choker setter has but a few seconds to protect himself from his error-a poorly set choker. As a study chief, you have much more time and help to protect yourself from your occupational hazard-a poorly designed study. Use this time wisely and make certain everything is in the "go" position before the study begins to move. A general rule of thumb at this point is to be certain you can defend everything you propose to do, either orally or in writing. If you can, you need not fear the bite of the line and are ready to prepare a contract.

\section{The Contract}

Now is the time to write a planning report or a study contract. In this contract you will relate the study to the field of hydrology (introduction), tell why you are undertaking the study (purpose), define the limits of the study (scope), describe the methods you will use (methods), and provide a preliminary reference list relating to the study (references).

Your contract will be widely read. Although your main concern will be to satisfy your supervisor, you also will want to pre-empt belated criticism. Study chiefs can make criticism productive. After all, you have been willing to consider constructive criticism in the design of your study. If not, you would not have prepared a study-planning report for everyone to review. But the investigator wants input at the beginning of the labor, not at the end. If you have done your homework, you will pre-empt all but superficial criticism. Remember that as study chief, no one has given the study design more thought than you, no one has reviewed existing data for this study in the detail that you have, and no one has designed and justified the parameter and measurement list as you have (table 6). If you carefully prepare the planning report, using the outline soon to be presented, the burden of proof"why this" and "why not that"- -lies with your critics. You have gone from the defensive to the offensive.

Build the conceptual framework for the components of the contract, the planning report, and begin to put the contract together. The contract must be much like a western corral; a small area (relatively short report) where different kinds of livestock (ideas and concepts) are held. Out west, we say that a good corral is "horse high, bull strong, and hog tight." This simply means, for your purposes, that the critics cannot jump, destroy, or find leaks in the planning report.

Here are the components of the planning report. Study them carefully. They have all withstood the test of time. Successful researchers were using these components to guide their study design long before we took pen in hand.

\section{Introduction}

The introduction should bring the study or study phase into focus. Although the introduction may be brief, it should act as a funnel: wide at first while discussing the broad relations of the general subject to the study, and then narrowing quickly to focus on the study under consideration. The reader should be able to read the introduction and have a clear "no doubt about it" understanding of either the subject or the problem. 
If you have any questions about the introduction, grab a few examples from your bookshelf and read the introduction of several books and papers. Chances are you have read numerous papers without really analyzing their introductory statements. You have probably taken the introduction for granted, but that is a luxury for readers, not writers. If you want the reader to understand what you are doing, and why you did it, then you must be brief as well as clear in the introduction.

\section{Purpose}

The purpose can be woven into the final part of the introduction. Experienced writers do it this way; and chances are that in most journal articles, the purpose is a part of the introduction. However, if you are inexperienced, it is probably best to make the purpose a separate section of the planning report. This organization may appear a bit artificial to an experienced editor but will frequently help your thinking.

The purpose must clearly define the problem to be solved, and must state clearly and accurately why the study should be undertaken. Keep in mind that the purpose is your opportunity to justify why you, a talented individual in your organization, should devote your time on the study.

Give the study purpose a lot of thought and talk to your peers about it-get their ideas as to its importance. Chances are you will be involved with the study for a year or more. Do not let any doubts linger in your mind as to why you are doing this study. Also, make certain the remainder of the study report supports the purpose.

\section{Scope}

A rifle scope is attached to the barrel and is oriented to point the barrel along the same line of sight as the scope. A well-aligned rifle scope images the target at the point of the bullet's impact. Your study scope also should be well aligned and it should define clearly what you plan to do. Specifically, the scope should define: (a) Where the study will be conducted; (b) when the study will begin and end; (c) the kinds of data to be collected; (d) the frequency and density of data collection (your data-requirement matrix is a part of the scope); (e) completion dates for collection; and (f) the use that will be made of the data, including reports. You might even wish to briefly state what you are not going to do. In writing the scope, keep in mind the corral concept-horse high, bull strong, and hog tight. Leave no doubt as to the boundaries of your study, nor the strength of the enclosure.

\section{Methods}

The methods section must describe the techniques that will be used to solve the problem. Published techniques should be referenced, including page numbers of manuals (for example USGS Techniques of Water-Resources Investigations and similar documents). Special techniques-those not commonly used in your organization, not listed in your organization's manuals, or difficult to locate - should be clearly and adequately described and referenced. Disciplinespecialist reviewers should be able to clearly understand from your methods section the techniques you plan to use.

If you need any special equipment, it should be listed in the methods section and completely referenced. Justify special equipment in some detail, for it will keep you from answering questions later.

Remember, the methods section is an extension of the scope. It merely tells in detail how you are going to carry out what you said you are going to do. The word "detail" in the above sentence is significant because the methods section must be so complete that should you leave the study, your successor should be able to follow the methods you described. All this does not mean that you cannot change techniques as the study progresses, but it does mean that you should provide at the beginning of the study complete methodology for carrying out the study.

\section{Budget, Manpower, and Expertlse}

This section should include source and amount of funds and a budget including salaries, travel, supplies, equipment, laboratory analysis, and other support items. Describe in detail the type of consultation you may need to complete the study, being certain to tie the need to the "Scope" and "Methods" sections. Explain in detail why such help will be needed for the successful completion of the study, and whether or not the help is available locally, or within or outside the organization. List the length of time you anticipate the help will be needed.

\section{Literature Review}

If you believe that the readers and reviewers are not familiar with a part or all of the subject, provide a brief literature review section in your planning report. You should be quite familiar with the literature that relates to the study. Being familiar with the literature is such an axiomatic requirement that it was not mentioned earlier in this report. 


\section{References}

List all references given in the methods section and others that are highly pertinent to the study. Do not list references just to be listing them. A short, wellthought-out reference list is much more useful than a padded, poorly developed list. Remember that one of the best ways to judge a study chief's expertise and knowledge of the subject is to review the references.

Now, let's look back at what was done. You have written a planning report that has Introduction, Purpose, Scope, Methods, Budget, Manpower, and Expertise, and Reference sections. It also may include a section for quality assurance. If done carefully, you have prepared a contract between your supervisor and yourself. The supervisor knows what you are going to do because you have explained it in clear, concise language in great detail. The supervisor now knows your expectations. You have now exposed your ideas and even your writing ability to the world. But also, you have built something. You have put together in clear, concise language a structure, that if carried out, will increase the hydrologic knowledge of the world in which we live. You have devised a plan to collect data and convert it to information. If you have followed the techniques provided, you will have a contract that meets the corral requirements-horse high, bull strong, and hog tight! Think back at this time and realize just how easy it really was; recall also that it was an intellectual exercise, not a mechanical activity.

However, the best news is yet to come! If you have carefully written the Introduction, Purpose, Scope, and Methods sections, you have completed from one-third to one-half of the final report! Think that over carefully. It means that after your data collection and measurements are made, you need only write the results and analysis sections. And, you can give some real thought to the results and analysis sections, because you no longer have to worry about writing the Introduction, Purpose, Scope, and Methods sections. You may wish to polish the introduction and other sections while the measurements are made for the study, but much of the work is over insofar as writing is concerned.

In "The Framework of the Study" section, the importance of sketching the expected relations between constituents was mentioned. The planning report you have just written is nothing more than an extension of these relations. You have put down on paper the plan; the plan no longer exists just in your brain where things can escape. The plan is on paper where it can't change unless you change it. More importantly, your eyes are helping the brain find flaws in the plan.

\section{EPILOG}

Most of the essential parts for the design of a surface-water quality study have been covered. To be certain, more could be said about some topics and probably too much was said about others. Be that as it may, if you followed the guidelines as well as supplied sufficient thought, you will have constructed a good planning report and will have made considerable progress towards the preparation of the final report.

You will not be satisfied with all parts of your planning and final reports. If you are satisfied with one or both, then you are not working hard enough. You have not practiced enough self criticism and are leaving the fault finding to others. Do not permit this-make critics work hard too; make them search for flaws in your work.

Satisfaction in study design and research comes with doing the best possible work you can. It comes with knowing that you have applied your knowledge, your thought processes, and your brain power towards solving a problem. And it comes with knowing that you have described your plan for the world to see.

The study chief who advances with each new assignment, both intellectually and in the complexity of the undertaken task, is conducting a true investigation. Successful study chiefs compete with themselves within their chosen discipline. Their second effort is superior to their first and so on, and each effort advances their understanding of their discipline. They are problem-oriented, and they direct their efforts at the heart of the problem-they probe for understanding. Successful study chiefs continuously ask the question listed in "The Framework of the Study" section, "Upon completion of the study, will my knowledge be significantly greater than before the study began?" Successful study chiefs know they cannot collect all the data they need to "prove" something. Indeed, they know that proof is an abstract and that disproof is just as valuable. Thus, they look for relations between hydrologic analytes and make assumptions about those things they cannot measure. Most importantly, successful study chiefs apply all the mental pressure and resources they can to the problem.

Successful study chiefs define the problem well and they build a framework, hypothetical or otherwise, around the problem. They have a mental concept of how the system works and build upon this conceptual framework. If it collapses on them, they alter their approach, using those concepts that worked in the first approach and discarding those concepts that were not fruitful. As Platt $(1964$, p. 353) stated, "The man to watch, the man to put your money on, is not the man who wants to make 'a survey' or a 'more detailed 
study,' but the man with the notebook, the man with the alternative hypothesis and crucial experiment, the man who knows how to answer your questions of disproof and is already working on it."

\section{REFERENCES}

Britton, L.J., Averett, R.C., and Ferreira, R.F., 1975, An introduction to the processes, problems, and management of urban lakes: U.S. Geological Survey Circular 601-K, $22 \mathrm{p}$.

Britton, L.J., and Averett, R.C., 1976, Variations in concentration of selected water-quality constituents in the Sacramento River at Bend Bridge, California: U.S. Geological Survey Water-Resources Investigations, No. 76-14, 15 p.

Chamberlin, T.C., 1897, The method of multiple working hypotheses: Jour. of Geology, v. 5, p. 837-848.

Chambers, J.M., Cleveland, W.S., Kleiner, Bert, and Tukey, P.A., 1983, Graphical methods for data analysis: Wadsworth statistical probability series: Boston, Duxbury Press, $395 \mathrm{p}$.

Cochran, W.G., 1977, Sampling techniques, (3rd ed.): New York, John Wiley, 428 p.

Conover, W.J., 1980, Practical nonparametric statistics, (2d ed.): New York, John Wiley, 493 p.

Dixon, W.J., and Massey, F.J., Jr., 1983, Introduction to statistical analysis, (4th ed.): New York, McGraw-Hill, $678 \mathrm{p}$.

Elliott, J.M., 1977, Some methods for the statistical analysis of benthic invertebrates, ( $2 \mathrm{~d}$ ed.): Freshwater Biol. Assoc. Sci. Pub. 25, 156 p.

Emmett, W.W., 1975, The channels and waters of the Upper Salmon River area, Idaho: U.S. Geological Survey Professional Paper 870-A, p. A1-A116.

Ewing, D.W., 1974, Writing for results in business, government and the professions: New York, John Wiley, $466 \mathrm{p}$.

Ghent, A.W., 1966, The logic of experimental design in the biological sciences: Bio. Science, v. 16, no. 1, p. 17-22.

Gilbert, R.O., 1987, Statistical methods for environmental pollution monitoring: New York, Van Nostrand Reinhold, $320 \mathrm{p}$.

Goerlitz, D.F., and Brown, Eugene, 1972, Methods for analysis of organic substances in water: U.S. Geological Techniques of Water Resources Investigations, Book 5, Chapter A3, 40 p.

Green, R.H., 1979, Sampling design and statistical methods for environmental biologists: New York, WileyInterscience, $257 \mathrm{p}$.

Guy, H.P., 1970, Fluvial sediment concepts: U.S. Geological Survey Techniques of Water-Resources Investigations, Book 3, Chapter C1, 55 p.
Guy, H.P., and Norman, V.W., 1970, Field methods for the measurement of fluvial sediment: U.S. Geological Survey Techniques of Water-Resources Investigations, Book 3, Chapter C2, $59 \mathrm{p}$.

Helsel, D.R., and Hirsch, R.M., 1992, Statistical methods in water resources: New York, American Elsevier Publishing Company, 522 p.

Hem, J.D., 1985, Study and interpretation of the chemical characteristics of natural water ( $3 d$ ed.): U.S. Geological Survey Water-Supply Paper 2254, 263 p.

Hirsch, R.M., Slack, J.R., and Smith, R.A., 1982, Techniques of trend analysis for monthly water-quality data: Journal of Water Resources Research, v. 18, no. 1, p. 107-121.

Hoaglin, D.C., Mosteller, Frederick, and Tukey, J.W., 1983, Understanding robust and exploratory data analysis: New York, John Wiley, 447 p.

Huber, P.J., 1981, Robust statistics: New York, John Wiley, $308 \mathrm{p}$.

Hutchinson, G.E., 1957, A treatise on limnologyVolume 1, Geography, physics, and chemistry: New York, John Wiley, $1015 \mathrm{p}$.

Iman, R.L., and Conover, W.J., 1983, A modern approach to statistics: New York, John Wiley, 497 p.

Koch, G.S., Jr., and Link, R.F., 1980, Statistical analysis of geological data-v. 1, Univariate Statistical Methods: New York, Dover Publications, 438 p.

McCall, C.H., 1982, Sampling and statistics handbook for research: Ames, lowa State University Press, 340 p.

Petts, G.E., 1984, Impounded rivers-Perspectives for ecological management: New York, John Wiley, 326 p.

Platt, J.R., 1964, Strong inference: Science, v. 146, p. 347-353.

Poole, R.W., 1974, An introduction to quantitative ecology: New York, McGraw-Hill, 532 p.

Reid, G.K., and Wood, R.D., 1976, Ecology of inland waters and estuaries ( $2 \mathrm{~d}$ ed.): New York, Van Nostrand, $485 \mathrm{p}$.

Ross, H.H., 1966, The logical basis of biological investigation: Bio. Science, v. 16, no. 1, p. 15-17.

Shapiro, S.S., 1986, Volume 3: How to test normality and other distributional assumptions: Milwaukee, American Society for Quality Control, $67 \mathrm{p}$.

Snedecor, G.W., and Cochran, W.G., 1967, Statistical methods (6th ed.): Ames, Iowa State University Press, $598 \mathrm{p}$.

Steel, R.G.D., and Torrie, J.H., 1980, Principles and procedures of statistics, a biometrical approach ( $2 \mathrm{~d}$ ed.): New York, McGraw-Hill, 623 p.

Steele, T.D., 1968, Digital computer applications in chemical-quality studies of surface water in a small watershed: Proc. of the IASH/UNESCO Symposium at Tucson, Arizona, Dec. 1968, vol. 1, p. 203-214.

Stevens, H.H., Ficke, J.F., and Smoot, G.F., 1975, Water temperature-influential factors, field measurement, and 
data presentation: U.S. Geological Survey Techniques Water-Resources Investigation, Book 1, Chap. D1, $65 \mathrm{p}$.

Stumm, Werner, and Morgan, J.J., 1970, Aquatic chemistry: New York, John Wiley and Sons, Inc., 583 p.

Taylor, H.E., and Averett, R.C., 1991, Descriptions of waterquality experiments in the Colorado River: in U.S. Geological Survey Toxic Substance Hydrology Program, U.S. Geological Survey Water-Resources Investigations Report 91-4034, p. 576-578.
Thornton, K.W., Kimmel, B.L., and Payne, F.E.,(eds.) 1990, Reservoir limnology ecological perspectives: New York, John Wiley, 246 p.

Velleman, P.E., and Hoaglin, D.C., 1981, Applications, basics, and computing of exploratory data analysis: Boston, Duxbury Press, 354 p.

Wetzel, R.G., and Likens, G.E., 1991, Limnological analysis: New York, Springer-Verlag, 2nd ed., 391 p. 